\title{
The Evolution of Aortic Aneurysm Repair: Past Lessons and Future Directions
}

\author{
Ricky Harminder Bhogal and Richard Downing \\ University of Birmingham \& Worcestershire Royal Hospital, \\ United Kingdom
}

\section{Introduction}

The history and evolution of aortic aneurysm repair demonstrates an important paradigm within surgery, namely the importance of surgical pioneers and innovators who have strived to achieve technical excellence and improve patient care. It also highlights the wider evolution of surgery from traditional open operative techniques to the modern minimally invasive procedures. The following chapter discusses the surgical innovators and the techniques they have described that have enabled the repair of both thoracic aortic aneurysms (TAA) and abdominal aortic aneurysms (AAA).

Aortic aneurysms represent a significant health risk particularly for the elderly population. AAA is the 14th-leading cause of death for the 60- to 85-year-old age group in the United States (10.8 deaths per 100,000 population). TAA by contrast is less frequent with an incidence of 10.4 per 100,000. Both AAA and TAA are known to increase in prevalence with advancing age and have an increased prevalence in males. The risk of aneurysm rupture increases with increasing aneurysm diameter over $5.5-6.0 \mathrm{~cm}$ and is the primary indication for the repair of both TAA and AAA. Therefore surgery to repair both AAA and TAA is either pre-emptive to prevent rupture or emergent to repair a rupture. Repair of TAA and AAA by either open or minimally invasive techniques significantly reduces the risk of rupture and improves patient mortality. The establishment of these techniques has required the development of procedures from embryonic thoughts in the minds of the surgeons of antiquity through to the utilisation of ever increasing modern technologies.

\section{History of aortic aneurysm repair}

The Ebers Papyrus of approximately 2000BC describes arterial aneurysms among diseases afflicting the Egyptians albeit the site of the aneurysms is not mentioned. Yet given Egyptian embalmers reluctance to open body cavities it is likely that the aneurysms were evident upon the external surface of the body. There is no convincing evidence to suggest that the ancient Egyptians attempted aneurysm repair, although it was advised "to treat it with a knife and burn it with a fire so that it bleeds not too much" (Thompson, 1998). Unlike atherosclerosis, no aneurysms have been found in Egyptian mummies.

The most important surgeon with respect to aortic aneurysm surgery in antiquity is the third century Greek surgeon, Antyllus, who should rightly be regarded as the 'Father of Aneurysm Surgery' if not vascular surgery as a whole. Indeed he has been described as a 'comet on the 
surgical horizon' for his pioneering work on aneurysm repair (Major, 1954). This innovative surgeon attempted surgical repair of abdominal aortic aneurysm which has led to the term the Antyllus method; ligation of the artery above and below an aneurysm, followed by incision into and emptying of the sac. Antyllus was also the first to recognize two forms of aneurysm. The developmental type caused by dilation, which pertains to this chapter, and those which follow arterial trauma. He also created a taxonomy related to an aneurysm's potential for rupture. Much of Antyllus's remarkable pioneering work and his surgical methods of aneurysmal repair would have been lost to history were it not for the writings of the Greek medical writer and physician Oribasius. It is clear that Antyllus also developed specific instructions for a number of operations including hydrocele repair and cataract surgery. He also listed the indications and contraindications for surgery and described the complications that could arise from the operations. In large part, Antyllus's operation for aneurysm remained the standard procedure until the 19th century thereby illustrating his surgical genius.

Antyllus's contribution toward the development of modern vascular surgery cannot be overstated. Indeed he should be held in the same regard as the dominant figure of Greek medicine, Galen who also described traumatic aneurysms and noted that rupture could be forestalled in some circumstances by external compression. Galen, the physician to the Roman gladiators, would have treated traumatic aneurysms following venesection in the cubital fossa- lesions which were easier to observe than AAA and TAA. Taken together, the work of Antyllus and Galen established the foundations for future surgeons to develop the techniques required for successful aortic aneurysm surgery and repair.

In the fifth century AD the Byzantine physician Aëtius of Amida described a now wellestablished principle of operative treatment of aneurysms in which proximal arterial control is followed by ligature from within the aneurysm of the orifices of inflow and outflow vessels, thus building upon Antyllus's method. In addition he described the clinical signs of aneurysms mentioning that they can occur in any part of the body including the head.

Unfortunately, there again followed a long hiatus in the history of aortic aneurysm repair. The next significant contribution was in 1452 by the French physician Jean Francois Fernel who observed that aneurysms could occur in the chest, adjacent to the spleen and within the mesentery of the bowel. It is not clear whether Fernel was referring to thoracic aneurysms at this stage. Andreas Vesalius offered the first clinical description of an aneurysm of the abdominal aorta, while his $16^{\text {th }}$ century contemporary Ambroise Pare stated that arterial wall degeneration can be caused by syphilis, that aneurysms may thrombose and that injudicious incision of an inflamed pulsatile mass may cause exsanguinating haemorrhage.

The English physicians and brothers William and John Hunter portrayed a unique experimental and clinical genius rarely present in late $18^{\text {th }}$ century medicine. They made significant advances in both the physiology and surgical repair of blood vessels and pioneered the treatment of peripheral aneurysms. Indeed their important contributions to vascular surgery have prevailed until today while their studies of aneurysm formation, pathology and treatment laid the foundation for modern aneurysm repair. John Hunter developed a successful operation for popliteal aneurysm based on his meticulous laboratory investigations on collateral blood flow which led to a more logical approach to these lesions with improved proximal arterial occlusion by ligature.

One of John Hunter's pupils, the English surgeon and anatomist Astley Cooper, applied Hunterian principles for ligation of aneurysms of common carotid and internal and external 
iliac artery aneurysms. In 1817 he was the first surgeon to ligate the abdominal aorta proximal to a leaking left iliac artery aneurysm.

The early 20th century saw an explosion in numerous novel attempts to repair and halt the inexorable growth of aneurysms in the decades before the development of modern vascular surgical techniques. Yet, despite extensive research and application of experimental techniques AAA repair remained unsuccessful until 1923 when the American surgeon Rudolph Matas renovated the approach of Antyllus and Aëtius of Amida and carried out endoaneurysmal ligature of peripheral aneurysms. The approach spared collaterals around the aneurysmal sac. Matas also first proposed the concept of endoaneurysmorrhaphy and performed the first successful aortic ligation on a human. The Canadian physician William Osler called him the 'Father of Vascular Surgery' but perhaps this would be better reserved for Antyllus. Other novel techniques for AAA repair included arterial walls that were scarified with talc, wrapped in polythene or cellophane or filled with meters of wire to which a galvanic current could be applied. Notably Albert Einstein was operated upon by Rudolf Nissen in 1949 using the polythene/cellophane technique, and survived six years after the operation when the aneurysm ruptured.

The 1950's was the decade which heralded the modern era of aortic aneurysm surgery. In 1951, Lam and Aram reported the first successful repair of a thoracic aortic aneurysm while in the same year the first successful AAA resection with allograft reconstruction was reported by Charles Dubost in Paris (Dubost C et al, 1951). In 1953 Bahnson reported a series of saccular aneurysms repaired using a technique of lateral resection with primary suture (Bahnson, 1953). The development of treatment modalities for thoracic aneurysms followed successful treatment of AAA almost akin to a domino effect. Most of the initial successful repairs involved the use of preserved aortic allografts, thus triggering the establishment of numerous aortic allograft banks. Simultaneously, Gross and colleagues successfully used allografts to treat complex thoracic aortic coarctations, including those with aneurysmal involvement (Gross et al, 1948). Ascending aortic replacement required the development of cardiopulmonary bypass and was first performed in 1956 by the American surgeons Cooley and DeBakey (Cooley \& DeBakey, 1957). They successfully replaced the ascending aorta with an aortic allograft. Successful replacement of the aortic arch with its inherent risk of cerebral ischaemia was understandably more challenging and was not reported until 1957 again by DeBakey et al (DeBakey et al, 1957). Although the use of aortic allografts as aortic replacement was widely accepted in the early 1950s, the search for synthetic substitutes was well underway prompted by the inevitable aneurysmal degeneration of such allografts. The synthetic material Dacron was introduced by DeBakey and by 1955, Deterling and Bhonslay believed that Dacron was the best material for aortic substitution (Deterling \& Bhonslay, 1955), a conclusion which pertains to the present time.

Finally, in 1966, Oscar Creech, a pupil of Rudolf Matas, emphasized the virtues of intrasaccular graft interposition now universally used for open aortic aneurysmal repair. Following in the footsteps of the ancient pioneering surgeons, later surgeons have developed the techniques of both open and minimally invasive aortic aneurysm repair.

\section{Open repair of abdominal aortic aneurysm}

\subsection{Open AAA repair}

The advances dating from Antyllus through to Oscar Creech led to the development of a standard operative procedure to repair AAA. More recently, non-invasive screening 
programs and a dramatic rise in the elderly population have led to an increased incidence of asymptomatic AAA. Despite adopting an aggressive surgical posture toward elective repair of AAA the incidence of ruptured AAA has continued to increase. Annually 35000 to 40000 aneurysms are repaired in the United States. AAAs are conventionally defined as a $\geq 50 \%$ increase in aortic diameter compared with the normal proximal aorta. Indications for surgical replacement of aneurysms are determined by weighing the risk of rupture against the surgical morbidity and mortality rates. Repair is generally indicated when the diameter of the aneurysm exceeds $5.5 \mathrm{~cm}$ (Lederle et al 2002), the annual expansion rate exceeds $1 \mathrm{~cm}$ per year or when the aortic aneurysm becomes symptomatic.

Comprehensive radiological imaging forms the basis of planning open AAA repair. Figure 1 shows the typical appearance of an AAA on transverse computed tomography (CT).

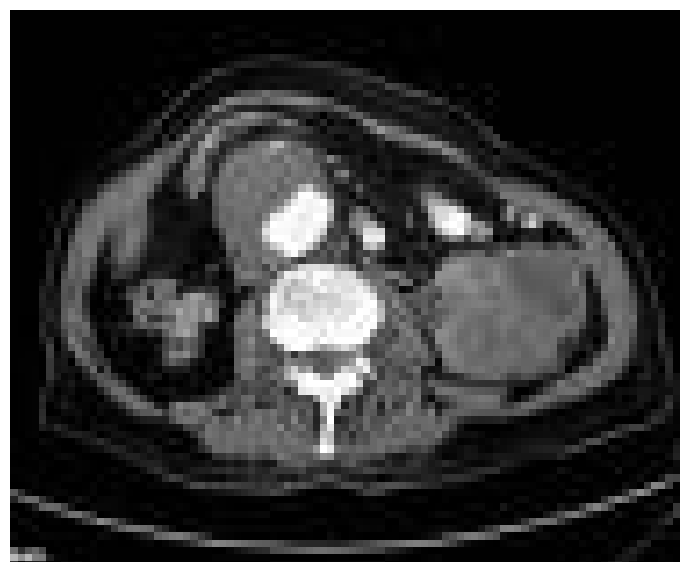

Fig. 1. Typical appearance of a fusiform AAA as seen on transverse CT. The aneurysm contains thrombus with radio-contrast seen within the lumen.

CT defines the aneurysm in terms of morphology, either fusiform or saccular, but more importantly defines the anatomy of the aneurysm neck. Ninety five per cent of AAA are infra-renal, ie. the neck of the aneurysm originates below the origin of the renal arteries and thus aneurysm replacement is associated with fewer post-operative complications when compared to supra-renal AAA replacement when the aneurysm neck originates above the renal arteries (see below). Aneurysms that involve the descending thoracic and abdominal components of the aorta can be described by the Crawford classification (Table 1). This classification is of practical use when considering intervention, for example, in choosing the extent of the incision and planning implantation. For instance a laparotomy will often suffice for repair of a type IV aneurysm whilst a thoraco-laparotomy is required for a type II aneurysm.

Open aneurysm repair using homografts and subsequently Dacron has successfully been employed to prevent rupture since the 1950s. Since Matas's original description of the surgical repair of AAA the operation has evolved to be applied in both the elective and emergency setting. The open surgical approach in the modern era is performed either via a trans-peritoneal or retroperitoneal exposure to obtain proximal and distal aortic control using vascular clamps (Figure 2). 


\begin{tabular}{|c|c|c|}
\hline Type & Proximal Extent & Distal Extent \\
\hline I & Left subclavian artery & Visceral Aorta (usually suprarenal) \\
\hline II & Left subclavian artery & Infrarenal aorta \\
\hline III & Mid-thoracic aorta & Infrarenal aorta \\
\hline IV & Diaphragm & Infrarenal aorta \\
\hline V & Mid-thoracic aorta & Visceral aorta (usually suprarenal) \\
\hline
\end{tabular}

Table 1. Crawford classification of thoraco-abdominal aneurysms.

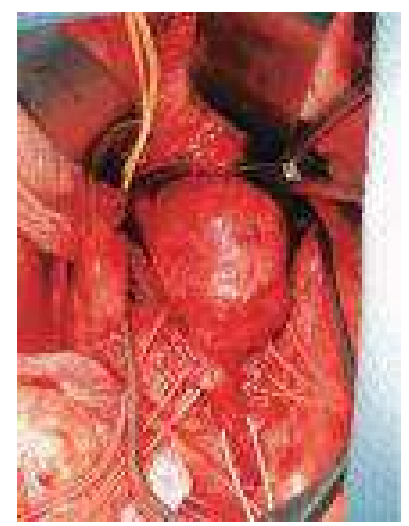

Fig. 2. An infrarenal AAA during surgical repair. A typical infra-renal AAA is seen with placement of a clamp to establish proximal aortic control. The iliac vessels have been controlled with vascular sloops to be clamped to achieve distal aortic control.

Intravenous heparin is administered, the aneurysm sac opened and back-bleeding branch arteries (lumbar and inferior mesenteric) are ligated. A prosthetic graft, usually made of Dacron, is sutured to the proximal aorta and the aorta proximal to the bifurcation (Figure 3).

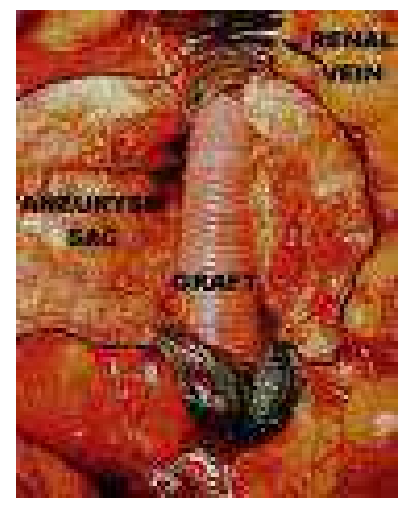

Fig. 3. An orthotopic Dacron graft has been sutured to replace the AAA. 
Demonstrates the satisfactory position of a Dacron graft sutured into the original site of the AAA.

If the AAA is aorto-iliac ie. the iliac arteries are also aneurysmal a bifurcated graft or ' $Y$ graft' is used and sutured to the iliac segments usually at the iliac bifurcation. Flow is restored to the lower extremities and the aneurysm sac closed over the synthetic graft. Although effective and durable in treating AAA and preventing rupture the operation has been associated with mortality rates of $>4 \%$ since the 1980 s although in large volume units, rates of $1-2 \%$ are now reported. This has provided the impetus for the development of minimally invasive or endovascular techniques. However, traditional open aneurysm repair may still be considered superior to endovascular repair (EVAR) because it provides secure fixation at all anastomotic sites, ligation of all lumbar branches and other aortic branches with virtual elimination of the possibility of endoleaks associated with EVAR (see below). In addition, open AAA repair offers complete treatment of aneurysmal disease with obliteration of the aneurysmal sac and debridement of its clot and atheromatous debris and most importantly is of proven durability. Of all the technical advantages of open repair, secure fixation at all anastomoses is probably the most important. Many authors submit that suture fixation with continuous polypropylene is superior to metallic barbs, hooks, and struts that are part of the current generation of EVAR devices (Clagett, 2008). Also it remains to be determined whether endostaplers, used during EVAR to provide aortic fixation, will adequately penetrate the diseased aneurysmal aortic wall. Hence, open repair still has a prominent role in the surgical treatment of aortic aneurysmal disease.

\subsection{Complex open AAA repairs}

Five per cent of AAAs are supra-renal where the aneurysm neck originates at any point above the origin of the renal arteries. Most infra-renal AAAs can be repaired safely under infra-renal aortic cross-clamping using the technique detailed above (Figure 2). However, juxtarenal (ie. an infrarenal neck inadequate for clamp placement) and suprarenal AAA's necessitate control of the aorta using suprarenal, inter-visceral, or supra-celiac aortic clamps. The procedure for repair remains essentially the same with suturing of a Dacron graft to the proximal and distal aorta following exclusion of the aneurysm but may necessitate mesenteric and/or renal arterial implantation into the graft. Anecdotal evidence suggests that inappropriate infra-renal clamping may cause renal embolization and a higher incidence of para-anastomotic pseudoaneurysms. Supra-renal clamping induces the risk of renal and gastrointestinal complications. Clamping between the renal arteries and the superior mesenteric artery (SMA) is associated with a disturbingly high rate of complications and should be avoided (Crawford et al, 1986). However, supra-celiac clamping avoids the need for retraction and manipulation of large aneurysms and may reduce the risk of embolization during dissection. In a study by Green and colleagues, patients whose aortas were clamped immediately above the renal arteries had higher perioperative mortality rates and a higher incidence of renal failure requiring dialysis than did patients whose aortas were clamped at the supra-celiac or infra-renal level (Green et al, 1989). However, some researchers have noted no differences in mortality rates with regard to the site of aortic clamping and comparable or even favourable cardiac morbidity rates with more proximal clamping (El-Sabrout \& Reul, 2001.). Direct comparison of early mortality after supra-renal and supra-celiac clamping with infra-renal clamping appeared to 
reveal a strikingly higher mortality rate after supra-renal and supra-celiac clamping. However, in-depth analysis reveals that most patients in the supra-renal and supra-coelic group had considerably more risk factors and underwent more extensive procedures than did those in the infra-renal group (Green et al, 1989). Myocardial infarction or congestive heart failure in the early post-operative period developed more often after supra-renal and supra-coelic clamping than after infra-renal clamping and was associated with a higher patient mortality. In a study by Sasaki et al, post-operative renal dysfunction developed in $50 \%$ of patients after bilateral supra-renal clamping, in comparison with only $8.4 \%$ after infra-renal clamping (Sasaki et al, 2000). Other authors have reported that the rates of transient postoperative renal dysfunction after elective supra-renal and supra-coeliac clamping was $12.6 \%$ as opposed to $3.35 \%$ after infra-renal clamping (Barratt et al, 2000). Importantly, chronic renal failure is a rare complication of openAAA repair.

\subsection{Complications of open AAA repairs}

Complications which may follow open AAA repair include not only cardiac and respiratory dysfunction but also visceral ischaemia/ischaemic colitis, trash foot, aorto-enteric fistula, sexual dysfunction, persistent chronic peri-aortitis and acute renal failure.

In 1974 Willard et al reported in a series of 6100 patients an incidence of visceral ischaemia and/or infarction of $1.5 \%$ (Willard et al, 1974). Such early studies advocated the reimplantation of the inferior mesenteric artery (IMA). The incidence of this complication has changed little over the decades but selective IMA re-implantation is now preferred if there is evidence or suspicion of colonic ischaemia.

Acute lower limb ischaemia following aortic surgery is commonly termed 'trash foot', an unwelcome complication that is associated with a high morbidity and mortality.

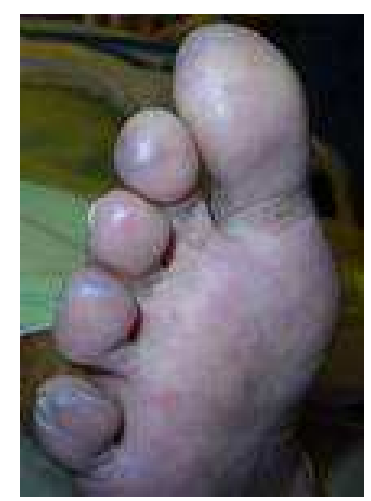

Fig. 4. The typical appearance of a trash foot following open AAA repair. The aetiology remains uncertain. Embolectomy may be required to restore limb perfusion.

The exact cause of the ischaemia remains uncertain, but it has been attributed to either athero-emboli from native arteries, thrombo-emboli from the prosthetic graft or thrombosis of small vessels in the distal arterial tree. It's reported incidence is $1.4 \%$ for open AAA repairs and may result in early or delayed amputation of digits or limb (Kuhan et al, 1997). The 30 -day mortality can be as high as $25 \%$. Attempts to reduce the incidence involve early 
mobilization and clamping of the iliac arteries, and irrigation of the aortic anastomosis and graft with heparin saline solution (Kuhan et al, 1997).

Aorto-enteric fistulas (AEF) are abnormal communications between the aorta and the intestine. It may occur after previous aortic aneurysm surgery with the duodenum as the most frequent site of fistulation (Saers et al, 2005). Presentation of AEFs is usually with massive gastrointestinal haemorrhage with or without associated aortic or graft sepsis. AEFs are difficult to diagnose with a high an index of suspicion needed in patients with previous aortic aneurysm surgery. If not treated promptly, AEFs are fatal (Voorhoeve et al 1996; Song Y et al 2008). Surgery offers the only definitive treatment. The favoured technique involves aortic debridement, repair of the intestinal defect and in situ aortic replacement which remains a high risk procedure with an operative mortality of 30-40\%. Extra-anatomic bypass is performed in patients with extensive local sepsis and is associated with an even higher mortality (Song Y et al, 2008). Endovascular techniques can achieve rapid control of bleeding associated with AEFs and avoid intervention in a hostile abdomen, while eliminating the complications associated with open surgery. However, placing new prosthetic material in an infected field may be hazardous. A recent review found that $44 \%$ of such patients developed recurrent graft infection; this complication was more likely in patients who had evidence of sepsis preoperatively and resulted in a higher 30-day and overall mortality; importantly life-long antibiotic therapy did not reduce recurrent sepsis (Antiniou et al, 2009). Hence AEFs require multi-modal and multi-disciplinary management to optimise patient outcome.

Surgical treatment of AAA's is appreciated to adversely affect sexual function, with the incumbent negative impacts upon the quality of life. The reported level of sexual dysfunction after open AAA repair is 30\% (Jimenez et al, 2004). Moreover, the incidence rises during the first post-operative year. Of course, patients with aortic aneurysms have atherosclerosis in other regions of the vascular tree and often have pre-existing sexual dysfunction. After AAA repair patients undergoing open repair report a greater magnitude of sexual dysfunction when compared to those undergoing EVAR (Prissen et al, 2004). Importantly EVAR and open elective AAA repair both have an impact on sexual function in the early postoperative period but EVAR appears to offer improved sexual function over the longer term (Jimenez et al, 2004).

As with any prosthetic material, Dacron, can become infected and result in an inflamed aorta/graft termed chronic peri-aortitis. This process can result in peri-aortic fibrosis and/or ureteral obstruction. Diagnosis involves clinical and radiological findings allied to blood inflammatory markers while treatment involves surgical intervention. However fibrosis and/or ureteral obstruction may recur (van Bommel et al, 2008).

The incidence of acute renal failure following complex AAA repair is discussed in detail above. Recent studies report the incidence of acute renal failure as approximately $10 \%$ (Kim GS et al, 2011). Despite this incidence the number of patients requiring dialysis after AAA repair remains low. However the reduction in relative incidence of acute renal failure after AAA repair using EVAR is a definite advantage of the minimally invasive approach. In a large cohort study by Wald et al the incidence of acute renal failure was reported as $6.7 \%$ (Wald et al, 2006). However EVAR was associated with lower odds of acute renal failure and acute renal failure requiring dialysis.

A recent study has shown that patient mortality after open AAA repair is most closely correlated with surgeon rather than institutional case volume (McPhee et al, 2011). 


\section{Open descending thoracic aortic aneurysm repair}

\subsection{Introduction to open TAA repair}

Diseases of the thoracic aorta remain among the most lethal of conditions and the most difficult to treat. Not surprisingly, the surgical techniques required to achieve successful TAA repair took longer to develop than those applied to open AAA repair but have evolved significantly during the past 20 years.

The procedure and outcome of ascending TAA repair are discussed within another chapter of the book and will not be considered here. The outcome from open repair of the descending TAA has steadily improved (Svennson et al, 1993). Many factors are responsible including advancements in anaesthesia, improved operative techniques, and advances in critical care. Although open surgical repair of this type of aneurysm once entailed great operative risk, experienced surgical centres now report acceptable surgical mortality and morbidity rates despite the inherent complexity of the repair.

\subsection{Surgical technique of open descending TAA repair}

Pre-operative assessment forms a key part of patient selection. Identification of pre-existing cardiovascular, pulmonary or renal risk factors enables development of a customised approach to open descending TAA repair. For example, the use of diaphragm-sparing techniques may be particularly helpful in patients with poor pulmonary reserve (Engle et al, 1999). The procedure is performed under general anaesthesia with the patient positioned in the right lateral decubitus position. A cerebrospinal fluid (CSF) catheter is placed in the third or fourth lumbar space to allow CSF drainage and pressure monitoring. The benefits of general hypothermia are well-established and for open descending TAA repair many centres routinely reduce the core body temperature to $32-34^{\circ} \mathrm{C}$ during surgery. Organ ischaemia remains a major source of morbidity. Moderate systemic heparinisation, permissive hypothermia and sequential aortic clamping are used routinely. The kidneys may be intermittently perfused with cold $\left(4^{\circ} \mathrm{C}\right)$ crystalloid to maximise renal hypothermia which affords better protection against acute renal dysfunction. To reduce the risk of perioperative coagulopathy and bacterial translocation after the aorta is opened adjacent to the visceral branches, separate balloon perfusion catheters may be used to selectively perfuse the coeliac axis and superior mesenteric artery by connection to a left heart bypass (LHB) circuit. Oxygenated blood flows to the abdominal viscera while the intercostal and visceral branches are reattached to the graft substantially reducing mesenteric ischaemic time. After repair of the aneurysm the operative field is rewarmed with warm saline to reverse cooling. A modified thoraco-abdominal incision is utilised for open descending TAA repair. The incision begins in the abdomen $3 \mathrm{~cm}$ below the costal margin and continuing over the sixth rib before curving cephalad just posterior to the tip of the scapula. Following division of the relevant muscular layers the lung is deflated, and the sixth rib is usually excised. The incision is completed by dividing the costal cartilage. The diaphragm is partially incised circumferentially to improve exposure and to avoid traction injury to the phrenic nerve. The pericardium is opened posterior to the phrenic nerve, and the patient given intravenous heparin to reduce the risk of thrombotic complications and to preserve perfusion of the intercostal and lumbar arteries which reduces the risk of spinal cord ischaemia. The left atrium is cannulated through the left pulmonary vein or the left atrial appendage. A pump with an inline heat exchanger is attached to the cannula, and the arterial inflow established through the left femoral artery or the descending thoracic aorta. Distal aortic perfusion is 
commenced when the cross-clamp is applied. By maintaining distal aortic perfusion during aortic reconstruction, LHB reduces spinal and visceral ischaemic time and prevents many of the complications seen after open AAA repair. Aortic control is established using the familiar proximal and distal paradigm using appropriate vascular clamps. It is vital at this stage to allow the important lower intercostal arteries to be perfused from below during of arterial construction of the proximal anastomosis and decrease the spinal cord ischemic time. This period requires carefully maintenance of normal proximal aortic pressure.

Vascular clamps are placed on the aortic arch between the left common carotid and left subclavian arteries. A vascular clamp is also applied to the left subclavian artery. The aorta is opened longitudinally and divided circumferentially a few centimetres beyond the proximal clamp. The haemodynamic effects of clamping and unclamping the aorta have been investigated since the mid-20th century as these effects are major contributors to the development of post-operative organ dysfunction (see below). Sequential clamping of the aorta remains an effective strategy for reducing ischaemic times. As the aorta is replaced from the proximal to the distal extent of the lesion, the aortic clamp is moved sequentially to lower positions along the graft to restore perfusion to newly reattached branch vessels. After the proximal anastomosis is completed using a non-absorbable continuous suture, the aortic clamp is repositioned onto the graft, flow restored to the left subclavian artery and the remainder of the aneurysm is opened longitudinally. An open distal anastomosis completes the repair.

As an alternative to the "clamp and sew" technique described above, left heart bypass can be used selectively to provide distal aortic perfusion during the repair. In this technique the aorta is opened longitudinally and separated from the oesophagus. Stay sutures are applied to the aneurysm wall, and haemostasis obtained by oversewing any bleeding intercostal or bronchial arteries. Blood salvage is accomplished using a cell-saving device, while blood may be re-infused using a rapid infuser system. The length of aorta that is replaced is dependent upon as assessment of the aneurysm at the time of exploration. Once adequate haemostasis is obtained, an appropriately sized, woven Dacron tube graft is anastomosed to the proximal aorta with a running polypropylene suture. The graft is then cut in a bevelled fashion to accommodate the intercostal arteries. Re-implantation of patent, lower intercostal arteries (T8 through T12) is also performed. The distal anastomosis is completed and the graft flushed. The aortic clamps are slowly removed, and suture lines checked for haemostasis. The patient is weaned from left heart bypass once the rectal or bladder temperature reached $36^{\circ} \mathrm{C}$. Protamine is usually administered and the atrial and femoral cannulae removed.

\subsection{Complications of open descending TAA repair}

Although recent advances in surgical techniques have improved the outcome of open descending TAA repair, significant mortality and morbidity is still encountered. Twenty seven percent of patients experience respiratory complications with prolonged postoperative ventilation (longer than 48 hours) and 11\% require tracheostomy. Available data demonstrates that pre-operative renal insufficiency and the extent of the aneurysm are important predictors of respiratory complications (Etz et al, 2007). Paraplegia is the most devastating sequel to TAA repair. Debate still pervades the optimal approach to perioperative spinal cord protection. Early experimental data showed that aortic clamping increased CSF pressure which is now kept less than $10 \mathrm{mmHg}$ for 3 days postoperatively by 
appropriate drainage through a CSF catheter. After removal of the drain delayed neurologic deficit should prompt its reintroduction to reduce CSF pressure (Estrera et al, 2003). The use of atrio-femoral bypass may have a protective effect in reducing paraplegia (Svennson et al, 1993). Subsequent to this latter study, other authors have reported encouraging results in reducing paraplegia rates by using only the clamp and sew for open descending TAA repair (Coselli et al, 2004). However, in a recent study involving 347 patients who had undergone descending open TAA repair and were specifically analyzed using propensity score analysis, the authors concluded that left heart bypass did not reduce paraplegia during repair (Coselli et al 2004). Although the overall incidence of paraplegia is low at $2.6 \%$, it can be concluded from the available literature that simple clamp and sew technique can be performed safely with acceptable results. The incidence of acute renal failure after open descending TAA repair is $3-14 \%$. If subsequent dialysis is required, patient mortality may rise to $30-60 \%$. The risk of renal failure also increases if shunting and bypass techniques are not utilised. Aside from the techniques outlined above mannitol may also improve post-operative renal function by increasing renal perfusion and by acting as a free radical scavenger.

A recent meta-analysis by Jonker et al conclusively showed the reduced rates of cardiac complications following minimally invasive TAA repair when compared to open repair. (Jonker et al, 2010). The incidence of myocardial infraction was 11.1\% following open repair compared to $3.5 \%$ after TEVAR. The reported incidence of stroke after open TAA repair varies between 2-18\% (Moon et al, 2007). Again in their systemic review Jonker et al showed that the TEVAR reduced the incidence of stroke (4.1\% TEVAR versus $10.2 \%$ open repair). It is important note that many of these studies have assessed total complications in the particular patient groups and clinically some patients with invariably suffer more than one complication.

\section{Aneurysm repair in the modern era}

\subsection{Minimally invasive aortic aneurysm repair}

In accord with the advancements in general surgery, the late 1990's witnessed the pioneering of thorascopic and laparoscopic aortic aneurysm repair. Unfortunately the introduction and advancement of endovascular techniques have overshadowed and perhaps forestalled major development of these surgical approaches. A brief overview follows.

\subsection{Thorascopic TAA repair}

The premise for the development of thorascopic TAA repair was to minimize surgical trauma and aid improved patient outcome relative to open TAA (Fukada et al, 2002). The use of thoracoscopy in thoracic surgery is known to decrease post-thoracotomy pain and lead to enhanced patient recovery (Dajczman et al, 1991; Kirby et al, 1993). The literature consists of only limited case reports and case series detailing the technique of thorascopic descending TAA repair although the advent of endovascular techniques have impaired the major development of this facet of aortic aneurysm repair, thorascopy have been invaluable for the field of thoracic surgery. Historically thorascopic TAA repair was not attempted in humans over concern of prolonged aortic cross-clamp time necessitated by a minimally invasive procedure. As discussed above, during open descending TAA repair, the duration of the aortic clamp period, intercostal artery reimplantation critical to spinal cord blood flow 
and the completeness of spinal cord reperfusion are risk factors for paraplegia. However, shortening aortic clamp time and complete reconstruction of the intercostal artery were considered problematic if visualisation were as restricted as the original pioneers of thorascopic TAA repair envisaged. However, the thorascopic approach would certainly reduce patient morbidity, post-thoracotomy pain and ventilatory complications (Dajczman et al, 1991).

As with conventional open and endovascular repairs, preoperative radiological imaging is essential. Contrast CT and Magnetic Resonance Imaging (MRI) may help to prevent postoperative paraplegia by visualizing the spinal artery of Adamkiewicz. The patient is placed in a right lateral decubitus position, as with open repair. The initial insertion site of the thoracoscope in the middle axillary line in the $4^{\text {th }}$ intercostal space. A second thorascopic port is inserted through which a fan retractor is placed at a point $5 \mathrm{~cm}$ anterior to the first incision. Under direct thoracoscopic visualization of the TAA a mini-thoracotomy is made in the $7^{\text {th }}$ intercostal space. This incision could be extended according to the location of the

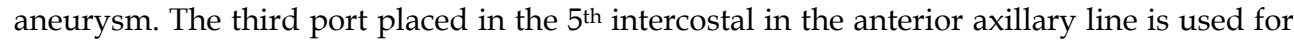
additional thorascopic views. The posterior surfaces of the aortic necks are dissected by the operator's hand introduced through the mini-thoractomy to avoid injuring the hemi-azgous vein. Umbilical tapes are placed around the aortic necks. Femoro-femoral cardiopulmonary bypass may be used at this stage. Two custom-made vascular cross-clamps are introduced via the first port and a fourth puncture wound made $4 \mathrm{~cm}$ anterior to the edge of the minithoractomy (Castronuovo et al, 2000). The aortic necks are transected after the placement of a proximal cross-clamp distal to the $9^{\text {th }}$ intercostal space and a distal clamp. Video-assisted graft replacement of the aorta is performed with continuous sutures by conventional instruments. Single re-implantation of the artery of Adakiewicz by use of a side-arm graft can be considered if radiological imaging has been obtained (Yamada et al, 2000). The principal benefits of the technique is that it enables the thoractomy wound to be made smaller by introduction of aortic clamps through puncture wounds, and while enabling a more accurate determination of the intercostal space to be incised by pre-observation of the thoracic cavity using a thoracoscope. However these techniques have not progressed to the establishment of total thorascopic TAA repair.

\subsection{Laparoscopic AAA repair}

The gold standard in the treatment of AAA remains repair with a prosthetic graft through an open approach (Creech et al, 1966). In the last 10 years EVAR has become an established alternative as a result of low failure rates and reduced mortality in the short term (Brewster et al, 2002; Brewster et al, 2003). However, over longer follow-up, complications following EVAR such as endoleaks, endograft migration, occlusion, and aneurysm rupture (see below) have been reported leading to reintervention rates in the order of $10 \%$ to $34 \%$ of cases (Verhoeven et al, 2004; Sampram et al, 2003; Becquemin et al, 2004). While EVAR has been gaining widespread popularity, the laparoscopic technique (through either a fully laparoscopic or a laparoscopy-assisted approach) for AAA repair has been under development (Dion et al, 1993; Kline et al, 1998; Cerveira et al, 1999; Edoga et al, 1998). Laparoscopic AAA repair was developed to overcome specific technical challenges during open surgery, such as bowel manipulation, bleeding control, and, mainly, the performance of vascular anastomoses, which might jeopardize the procedure success rate (Kolvenbach et al, 2004; Coggia et al, 2004). In some instances the insertion of a hand inside the insufflated 
abdominal cavity restores tactile feedback to the surgeon, who is able to locate the aneurysm neck and iliac arteries, thus adding to the visual evaluation of the anatomy and quality of the tissues. The internal hand also compensates for lack of the tri-dimensional vision encountered in laparoscopy.

For total laparoscopic AAA repair the patients the patient is positioned at 45-degree right decubitus position. The abdomen is hyper-extended and draped from the right midclavicular line to the left posterior axillary line.

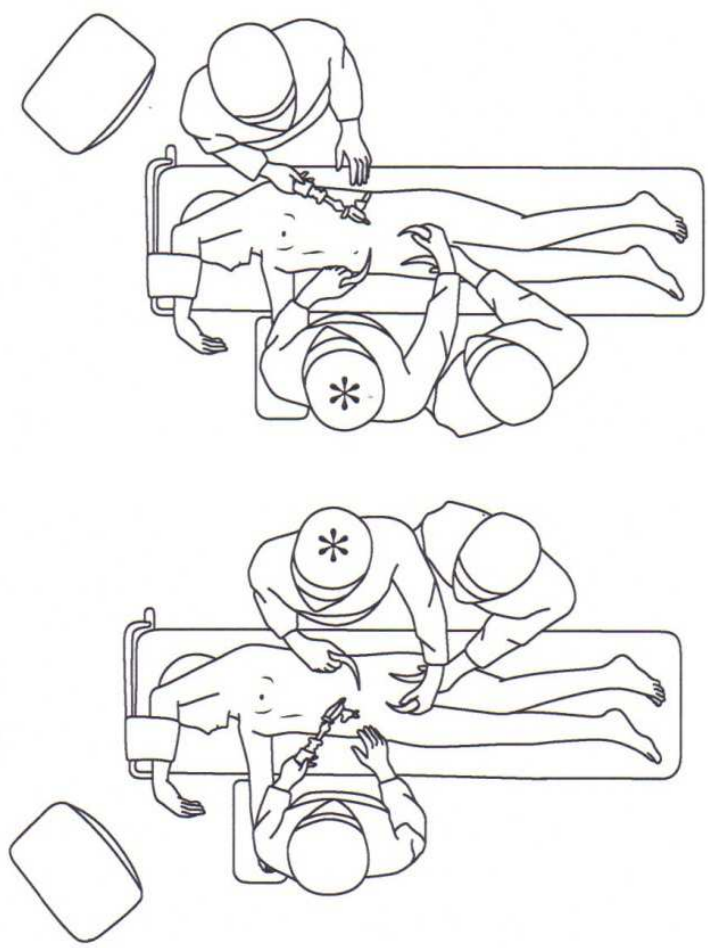

Fig. 5. The position of the operative surgeon and assistant for laparoscopic AAA repair.

Figure 5 demonstrates the position of the operating team at the commencement of the procedure. The patient lies in the semi-decubitus position on the right. The operating surgeon $\left.{ }^{*}\right)$ stands on the right of the patient. After retrocolic dissection the operating surgeon $\left(^{*}\right)$ stands on the left of the patient (lower panel) to perform endoaneurysmorrhaphy and laparoscopic anastomosis. (Taken from Chiu et al, 2008)

Initially, a sub-umbilical incision is made and a Veress needle inserted into the abdominal cavity to create a carbon dioxide pneumoperitoneum. A laparoscopic port is then inserted. Two additional laparoscopic ports are inserted in the midline above and below the first one port. By using these three ports, the peritoneal cavity is inspected. In hand-assisted laparoscopic AAA repair a midline mini-laparotomy incision of approximately $7-8 \mathrm{~cm}$ is first made for insertion of a laparoscopic omni-port-site device. Through the omni-port, the 
non-dominant hand of the surgeon is introduced into the abdominal cavity without any loss of insufflation. After the mini-laparotomy is performed, a laparoscopic port is placed in the epigastrium. With their non-dominant hand, the surgeon gently pushes bowel loops toward the right side of the abdominal cavity aided by tilting the operating table to the right and in the Trendelenburg position (not exceeding $30^{\circ}$ ).

Whether total laparoscopic or hand assisted AAA repair is used the initial dissection and mobilisation of the descending and sigmoid colon is carried out. The paracolic gutter is incised to expose the retroperitoneum and the splenic flexure detached from the splenic hilum. The descending mesocolon is dissected medially leaving Gerota's fascia, the ureter and gonadal vein intact. Following the landmark of the gonadal vein, the dissection is performed cephalic to the renal vein. The surgeon and assistant then move to the left side of the patient (Figure 5).

Three additional laparoscopic ports are then inserted. Three sutures serve as stay sutures to hold the left hemicolon apron. The traction sutures and right decubitus position help exposure of the retroperitoneal space. A laparoscopic fan retractor is used to keep the visceral organs away from the dissection. The aneurysmal neck and bilateral common iliac arteries can be isolated to facilitate the clamping of the aorta. The lumbar arteries behind the aneurysm and the IMA can be visualised, clipped and divided. Heparin is given prior to aortic clamping. Two additional laparoscopic ports are inserted for laparoscopic vascular clamps. A stab incision over the aneurysm allows assessment of the amount of collateral flow. The aorta is transected. The entire aneurysm is dissected free using electrocautery. A segment of Dacron graft is inserted into the abdomen and the proximal anastomosis between the aorta and the prosthesis is performed under direct vision with conventional but long instruments, according to the technique described by Oscar Creech (Creech et al, 1966). The proximal anastomosis is carried out using a $15 \mathrm{~cm}$ suture staring from the far side and running the dorsal aspect of the anastomosis. The other suture is used to finish the remaining anastomosis. The distal anastomosis is performed in the same way. The laparoscopic clamps are then removed. Afterward, the IMA is sewn or re-implanted, depending on left colon vascularisation. The aneurysm wall and the posterior parietal peritoneum are closed to cover the prosthesis in the conventional manner. Laparoscopic AAA repair has been applied to the repair of even complex AAA such as juxta-renal repair (Coggia et al, 2008).Although there remain proponents within centres performing laparoscopic AAA repairs routinely, it is likely that the approach will remain a niche in the field of surgical options for AAA.

\section{Endovascular aneurysm repair (EVAR)}

In tandem with a global movement towards minimally invasive techniques in all branches of surgery, endovascular techniques have become the treatment of choice for many aneurysmal conditions of the aorta reinforced by the mortality of open aneurysm repair. The concept centres on the endoluminal deployment of a covered stent graft which effectively shields the aneurysm wall from systemic arterial pressure and thereby, prevents aneurysm rupture. Since the first published report of stent graft implantation for AAA in humans in 1991 suggested that this approach was feasible (Parodi et al, 1991), a surge in both the number of EVARS performed and technological improvements in stent graft design account for a steady upward trend in stent graft use as reflected in administrative databases. Indeed, some consider EVAR to be the procedure of choice for 
AAA (Cowan et al, 2006; McPhee et al, 2007). The pace of technological evolution of EVAR has been rapid in comparison to the two millennia required for the development of successful open aneurysm repair.

Diffusion of this technology, although widespread, has been met with both enthusiasm and scepticism. Advocates of traditional open surgical techniques maintain that EVAR is costly and that long-term outcomes for patients are inferior. Rather than relying on sutures to provide fixation, as in open repair, endovascular stent grafts rely on radial forces of selfexpanding stents for fixation or self expand in concert with active fixation using hooks or barbs at the proximal aorta fixation site. With longer follow-up now being achieved after EVAR, $>97 \%$ 5-year and $>94 \%$ 9-year rupture-free survival has been observed (Brewster et al, 2006). Pre-procedural planning using CT as its backbone is the most critical component of a technically successful EVAR. Advances in imaging have had a major role in the development of these complex endovascular procedures: CT images are reconstructed on three dimensional imaging work-stations and 'centreline of flow' reconstructions are used to design the customised endoprotheses (Figure 6).
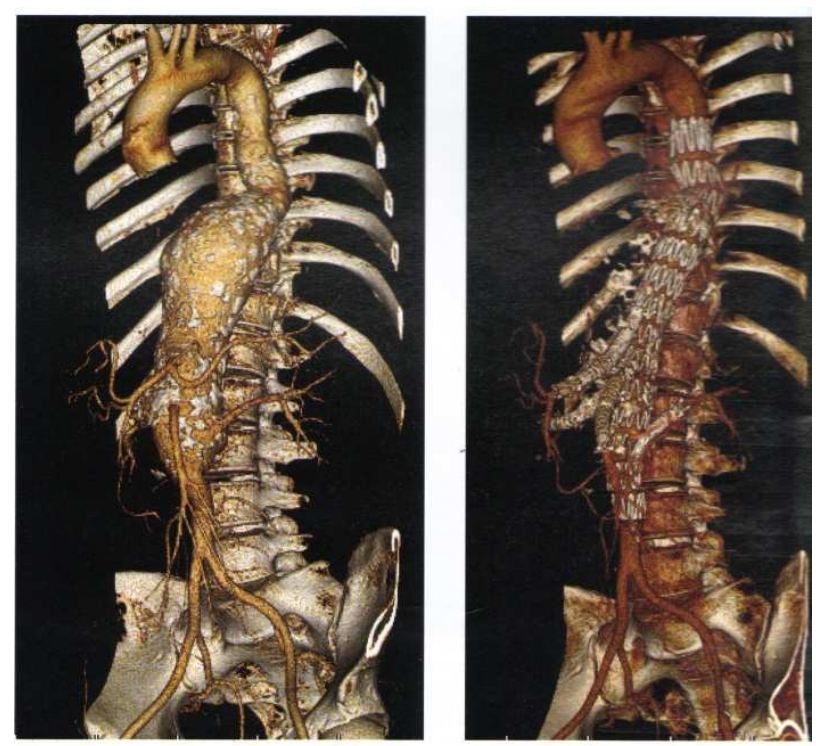

Fig. 6. Three-dimensional volume rendering reconstruction of a computed tomography angiogram performed before (left) and after (right) implantation of a four-branch endograft to treat a type III thoracoabdominal aneurysm. The bridging stents between the branches and the four target vessels are implanted from a brachial approach (Taken from Haulon et al, 2011).

Furthermore, intra-operative imaging can now incorporate on-table CT with 3-D reconstruction to improve the accuracy of graft placement and decrease fluoroscopy time and contrast media volumes. EVAR is a great advance but one must not lose sight of the fact that from a purely technical standpoint, open aneurysm repair is a superior operation. EVAR has been adapted for the treatment of AAA (herein termed EVAR) and TAA (TEVAR). Each procedure is discussed below. 


\subsection{Anaesthetic considerations for TEVAR \& EVAR}

Anaesthesia for TEVAR must accommodate the potential risk of conversion of the operation to open TAA repair. The risk of open conversion of TEVAR is decreasing with improvements in endoluminal prostheses and increased surgical expertise. Pre-operative assessment for TEVAR has tended to address the typical issues relating to general anaesthesia in a vascular patient. TEVAR should be classified as a high risk surgical procedure. The intra-operative anaesthetic goals during TEVAR are to provide haemodynamic stability while preserving cardiac, spinal and splanchnic blood flow. In addition, the maintenance of intra-vascular volume, adequate tissue oxygenation and body temperature is required. Accordingly, both general and regional anaesthetic techniques have been used successfully in the treatment of patients with descending TAA When combined with neurological monitoring and trans-oesophageal echocardiography (TOE). Care must be taken to ensure tachycardia and hypertension is avoided as this may impair spinal cord perfusion. The use of new self-deploying stents has meant that earlier manoeuvres such as ventricular asystole (Dorros et al, 1996) and ventricular fibrillation (Kahn et al, 1998) are not required for a 'still' operating field. Whilst an endoluminal balloon is being used to 'seal' the aortic wall after stent deployment (see below), a patient may experience significant haemodynamic stress, especially if baseline cardiac function is poor. Vasopressors and inotropes must be available to manage haemodynamic instability. Cardiac complications are the most common serious peri-operative adverse events of EVAR (Prissen et al, 2004) and the most common cause of late death (EVAR Trial 1, 2005). Hence patient selection must include careful risk stratification of co-morbidities. The Society for Vascular Surgery of America has recommended a medical co-morbidity grading system for EVAR that emphasizes cardiac, pulmonary, and renal status but also includes hypertension and patient age as relevant risk factors. This scoring system aids in patient selection and provides a framework for uniform data collection patterns intended to facilitate analysis of outcomes for EVAR. When a decision is made to proceed with EVAR, it can be performed under general anaesthesia, local aesthetic with sedation, epidural, or spinal block. Again for a patient undergoing EVAR the very small risk of conversion to open repair must be accommodated in operation planning.

\subsection{EVAR for TAA (TEVAR)}

Non-invasive repair of descending TAA has become particularly attractive but to justify its use the associated mortality and morbidity rates need to be equal to or better than those of open surgical repair. Dake et al reported the first endovascular TEVAR in 1994 (Dake et al, 1994) which ushered in a new era in the treatment of thoracic aortic disease. TEVAR is emerging as the preferred treatment strategy in a majority of patients, as increasing data suggests that it may be performed with lower peri-operative morbidity and mortality rates with similar mid-term survival, when compared with standard open TAA repair (Bavaria et al, 2007; Jackson et al, 2007). However, anatomic constraints, principally related to required endograft landing/seal zones and the suitability of femoral and iliac access vessels for endograft introduction excludes a significant number of patients, many of whom are not ideal candidates for open surgery (Jackson et al 2007). With regard to landing zones, both length and diameter must be considered with a required seal zone length of $\geq 2$ to $2.5 \mathrm{~cm}$ for all available devices. The endografts are usually oversized by $10 \%$ to $15 \%$, and thus, the adequate seal zone diameter ranges from 18 to $42 \mathrm{~mm}$ depending on the device used. 
Conventional TEVAR seal zones generally extend from zone 2 to zone 4 using a landing zone map.

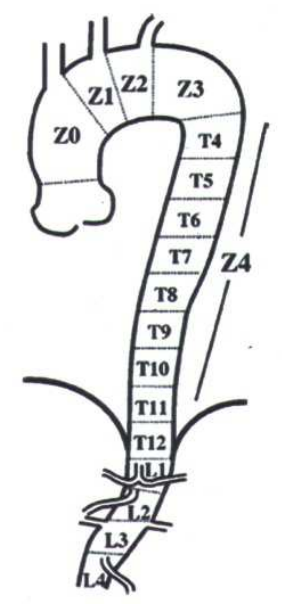

Fig. 7. The landing zones required for TEVAR.

Fig. 7 demonstrates the aortic landing zone map devised by Ishimaru. Conventional TEVAR landing zones are between zone 2 just distal to the left common carotid artery, and zone 4 to the level of the celiac axis. Distal landing zones in zone 4 may be preformed in conjunction with visceral debranching procedures (Ishimura 2004).

In this manner, endograft coverage may span regions of thoracic aorta between the left common carotid (CCA) and coeliac axis. The coeliac axis may occasionally be covered if necessary to achieve an adequate distal seal. Coeliac coverage is generally safe in situations in which the celiac artery is small in diameter and the SMA large and the gastroduodenal artery patent which will feed the coeliac distribution after coeliac coverage. Furthermore, if the right hepatic artery originates from the SMA, coeliac coverage should be well tolerated. Other seal zone considerations include the absence of excessive thrombus or calcification, which might impair endograft apposition to the aortic wall. For conventional TEVAR, the endografts are generally introduced via the femoral vessels, although introduction via the iliac arteries or even the infra-renal aorta may be necessary in some cases if the femoral vessels are unsuitable because of inadequate size or heavy calcification. The proximity of the oesophagus to the aorta in the intra-thoracic and upper abdominal regions makes TOE an attractive imaging modality for guiding placement of the endograft and detecting endoleaks after endograft deployment (see below). Precise placement of the endograft is essential to ensure exclusion of the aneurysmal sac from aortic flow. The endograft system can be clearly visualised in the aorta, from guidewire insertion, to balloon inflation and stent expansion. Aside from TOE, intra-operative CT and/or fluoroscopy can also be used to monitor the endograft system.

\subsection{EVAR for AAA (EVAR)}

Despite the reduction in mortality rates of open AAA repair from 20 to $5 \%$ in the past 30 years (Rickenbach et al, 2004) there are still several complications associated with this 
approach as illustrated above. It remains an invasive procedure with mortality rates rising sharply in those with co-morbid disease such as coronary artery disease and renal failure while recovery can be protracted resulting in reduced quality of life. Such problems combined with the high number of patients for whom open AAA was contraindicated prompted Volodos et al in 1991 to report their clinical experience of using self-fixing synthetic remote endoprosthetics for aorta reconstruction (Volodos et al, 1991). In the same year Parodi et al reported repair of AAA in five subjects using an endovascular approach with a modified stent and graft material (Parodi et al, 1991). The stent graft system reported by Parodi was initially developed and patented by Lazarus in 1987 (Lazarus et al, 1987).Although in these early studies reflux was found at the distal end of the graft which necessitated re-intervention, EVAR was established as a feasible treatment for AAA and more importantly safe for the patient.

The basic design of all endografts is similar: the aortic aneurysm is crossed by a tubular graft that has a wide diameter ( 20-36 $\mathrm{mm})$ and supported by stents along its length. The tube either bifurcates into two smaller diameter stent grafts that fit into the iliac arteries, or it decreases in size to locate in one iliac artery. Due to rapid commercialisation there are numerous EVAR devices available on the world wide market. The feasibility of EVAR like TEVAR depends mainly on anatomic factors that represent the important predictors of success. Aside from the indications of either an asymptomatic aneurysm of appropriate maximal diameter, or a small aneurysm with features putting it at increased risk of rupture, patients being considered for EVAR must fulfil several anatomic criteria. These include 1) ilio-femoral access vessels that will allow safe insertion and deployment of the device, adequate seal, and sufficient length to provide axial support for the graft and 2) an infrarenal aortic neck of adequate length, limited angulation, and appropriate diameter. These features, as well as the presence or absence of thrombus and calcium at each level of fixation are evaluated using CT. Anatomic selection criteria for EVAR are based principally on characteristics of the proximal infra-renal neck, aneurysm sac and iliac arteries. An unfavourable neck anatomy is the most frequent cause for exclusion from EVAR (Iezzi et al, 2001). The guidelines for EVAR are constantly being redefined, mostly as a result of increasingly operator experience and improvement in stent-graft technology. Although, with new technology the number of patient's eligible for EVAR will increase, complex aortic anatomy will be a significant limitation, at least for the foreseeable future and is likely to ensure that open AAA repair will continue to form an essential part of vascular surgery.

EVAR, as with TEVAR, begins by the surgeons gaining access to both femoral arteries typically through small groin incisions, although a totally percutaneous approach has been reported with low complication rates and high incidence of technical success (Lee et al, 2007). Therefore, both the femoral and iliac arteries must be patent, have as little tortuosity as possible, and one of them must allow a catheter, up to 24 French $(\mathrm{Fr})(8 \mathrm{~mm})$ in diameter, to be introduced to the aorta. In some patients with AAA the arteries are too small to allow access (Velazquez et al, 2001). In addition some patients have concomitant vascular disease, so the femoral and iliac arteries can be arteriosclerotic or tortuous which denies access (Wolf et al, 2001). Calcification may also compromise passage of the stent delivery sheath. After bilateral access is obtained, a marking angiogram is typical to confirm pre-operative CT measurements and identify the exact location of the lowest renal artery. Most devices follow with ipsilateral main body insertion and deployment at the infra-renal neck, wire cannulation of the contralateral "gate," contralateral limb deployment, balloon angioplasty to fully expand the device, and completion angiography. Technical success is achieved when 
there has been successful access to the arterial system using a remote site, successful deployment of a patent stent graft the stent graft with secure proximal and distal fixation and absence of either a type I or type III endoleak (Chaikof et al, 2002). Patients who undergo EVAR or TEVAR need regular clinical follow-up with appropriate imaging for the remainder of their lives because of the potential for stent graft migration and other causes of sac repressurization that put the patient at risk of aneurysm rupture. CT is the gold standard for follow-up imaging. Concerns with using CT for follow-up include the cumulative effects of radiation exposure and the effect of repetitive administration of intravenous contrast on renal function. MRangiography is an alternative for follow-up of most endograft devices but is costly, time consuming, and not universally available. Duplex ultrasound is preferable but bears the limitations of relatively small numbers of accredited vascular ultrasound technicians and the risk of inter-operator variability. Wireless pressure monitoring of the aneurysm sac using a small sensor implanted at the time of EVAR has been proposed as an alternative to other imaging modalities, but no long-term studies currently demonstrate its efficacy in preventing AAA rupture after EVAR (Kurosawa et al, 2007). Efforts to find the optimal method for minimizing the frequency and inconvenience for the patient of followup visits while maximizing freedom from aneurysm-related death are ongoing. The first generation stents were suitable only for treating infra-renal aortic aneurysms with a long narrow neck, but subsequent device evolution has led to the situation where few aortic aneurysms cannot be treated by endovascular means. Continued development of grafts is likely to lead to application of the technique to increasing numbers of complex AAA's.

\subsection{Complications of TEVAR \& EVAR}

Many adverse events may accompany EVAR as it is a technically complex procedure typically performed on a high-risk, elderly patient population. This is particularly true of patients undergoing TEVAR. Hence, although the incidence of paraplegia is lower with TEVAR, it remains one of its most dreaded complications. The aetiology probably differs from that encountered after open surgery in that no aortic cross-clamping is required and most likely arises secondary to coverage of important intercostal or other collateral arteries supplying the spinal cord. Some institutions have introduced CSF drainage as described above for open TAA repair (Fuchs et al, 2003). However CSF catheters have their own related morbidity in the form of meningitis, CSF leak and epidural haematomas. In patients with high risk of spinal ischaemia additional intra-operative neurological monitoring with trans-cranial motor evoked potentials and/or somatosensory evoked potentials are useful.

Blood loss following EVAR can be difficult to quantify, as it is often lost around the sheaths and catheters and can be retroperitoneal in the case of EVAR if an injury to femoral or iliac vessels occurs. In addition, TEVAR involves the liberal use of radiographic contrast to assist in appropriate deployment of the graft, ensure exclusion of the aneurysmal sac and determine branch vessel patency. The administration of radio-contrast media can lead to acute kidney injury which is usually reversible albeit its development is associated with adverse outcomes (Rudnick et al, 2008). There is no specific treatment for radio-contrast induced acute renal failure other than supportive management although preventive measures such as hydration with isotonic sodium bicarbonate and administration of the antioxidant acetylcyteine may reduce the risk (Merten et al, 2004).

Myocardial responses to aortic cross-clamping are well documented. The degree of cardiovascular and systemic effects depends on the level at which the cross-clamp is applied. The higher the clamp is placed, the greater the haemodynamic disturbance. Unlike 
open aortic surgery, TEVAR does not involve extended periods of aortic occlusion. Although the balloon is usually deflated within 15-20 seconds during TEVAR, patients with coronary artery disease or left ventricular dysfunction may respond poorly and run a high risk of myocardial ischaemia.

The above complications of EVAR procedure relate to the peri- and post-operative period. One of the most common adverse events following EVAR is the need for a secondary intervention. Data from the EUROpean collaborators on Stent/graft Techniques for Aortic Aneurysm Repair (EUROSTAR) registry of 2846 patients treated from December 1999 until December 2004 revealed that EVAR resulted in a cumulative incidence of secondary interventions of $6.0 \%, 8.7 \%, 12 \%$, and $14 \%$ at $1,2,3$, and 4 years, respectively (Hobo et al, 2006). Secondary interventions are typically performed when the aneurysm has become repressurized because of incomplete exclusion of blood flow from the sac. The term "endoleak" was created in 1996 to describe this complication (White et al, 1996). An endoleak is defined as the persistence of blood flow outside the lumen of the endograft but within an aneurysm sac or adjacent vascular segment treated by the graft (White et al, 1996; GonzalezFajardo et al, 2002). Endoleaks may occur because of misplacement or poor sizing of an endograft, endograft fatigue and displacement or distortion of the endograft material. These latter factors represent device failure which in the modern era has largely been overcome as a result of device development. Endoleaks have been classified into types I to IV based upon the underlying cause and anatomical site of origin. Each is discussed below.

Persistent flow around the attachment sites (proximal or distal) of the endograft due to inadequate or ineffective seal at the graft ends is classified as a type I endoleak. Type I endoleaks may occur in up to $24 \%$ of patients following TEVAR is the most frequently encountered, usually results from technical error and may eventually result in graft failure. Type I endoleaks usually require additional stent-graft deployment. .which may increase complication rates and adversely affect patient quality of life. Type I and type III endoleaks (see below) are treated immediately to halt peri-graft flow or flow between modular components.

An endoleak may also occur because of retrograde flow into the aneurysmal sac from a patent collateral branch vessel (type II endoleak) and is not of major concern. The endoleak usually resolves spontaneously after 6 months. Type II endoleaks are typically managed expectantly with intervention reserved for persistent endoleaks in the presence of aneurysm sac enlargement. The presence of a persistent type II endoleak for $\geq 6$ months, however, has been associated with aneurysm enlargement, increased rate of secondary interventions, and even aneurysm rupture (Fairman et al, 2006; Jones et al, 2007). Secondary interventions can range from diagnostic angiography to endograft removal with conversion to open repair.

Flow into the aneurysmal sac because of leakage between modular segments of an endograft is classified as a type III endoleak. This is probably more common in the thoracic aorta because of greater haemodynamic stress causing early or late graft material fatigue. Management via the endovascular route using a covered stent to reline the failing endograft is usually appropriate. A related cause of endoleak and potential complication of EVAR is device failure. The integrity of stent graft materials and maintenance of proper positioning within the aneurysm are critical in preventing pressurization of the aneurysm sac and rupture. Material failure includes fracture of any of the metallic components of the stent graft, including stents, hooks, or barbs, or tears in the fabric component of the stent graft. Loss of proper stent graft position can occur for many reasons. Material failure, inadequate proximal or distal seal zone, aneurysm remodelling after EVAR, or features of the vessel, 
such as thrombus or calcium, that limit stent purchase, have all been implicated in the migration of stent grafts. Each of these modes of failure must be analyzed within the context of their clinical significance. A stent fracture that leaves the graft fabric intact and is not in a critical region for maintaining fixation would likely need only follow-up, whereas modular component separation resulting in a large type III endoleak will require urgent intervention to restore stent graft integrity.

Flow detected in the aneurysmal sac by completion angiography may occur due to porous graft material. This is termed a type IV endoleak and may be difficult to distinguish from other types of graft leakage. Its diagnosis is made after exclusion of any other identifiable source of endoleak. Type IV endoleaks rarely occurs with modern stent graft design.

Type $\mathrm{V}$ endoleaks or 'endoleak of undefined origin' (endotension), although still reported (Iyer et al, 2007), but are much less frequent after modification of the Gore Excluder device in 2004 to a low-permeability expanded polytetrafluoroethylene layer (Tanski et al, 2007). Endotension is the continued pressurisation of the sac with subsequent sac enlargement in the absence of an apparent endoleak. It is may be caused by pressure transmission through a sealed of thrombosed endoleak (Kamineni et al, 2004). Controversy surrounds the nature of this type of endoleak and its management. An increase in aneurysm size can occur with endotension, but if there is no demonstrate endoleak or the aneurysm is shrinking in size, additional intervention is usually not required. Several procedures are possible: open replacement of the graft, wrapping the endograft with a new graft at laparotomy, and endovascular relining of the stent-graft. Conversion to open repair usually treats endotension satisfactorily (Lin et al, 2003).

Stent fatigue and fracture are also a problem following endovascular procedures. Ten per cent of all stent grafts have fractured within 4 years (Jacobs et al, 2003). The fracture of a stent strut may lead to a Type III endoleak, or if the attachment barbs and hooks fracture, the stent graft may migrate to form a Type I endoleak. Many stents allow initial deployment which allows partial re-positioning, as no repositioning can be performed when the graft is fully deployed. Inaccurate deployment will also lead to the increased use of extenders, thus increasing the probability of Type III endoleak (Zairns et al, 2003). Although many of the stents grafts do allow some manoeuvrability post-implantation, this is mostly in the form of moving the stent down the aorta. Thus if barbs/anchors have been deployed, too much movement may itself cause dissection of the artery. Kinking caused by fracture of the stent or insufficient support given to the graft can result in obstructed of a bifurcated limb (Corbett et al, 2008) which often leads to the need for endovascular re-intervention being required. EVAR device migration remains a major problem. Fixation devices (endostaplers) along with new stent graft designs may be important in preventing graft migration. Such approaches appear to work in animal models with relatively thin, non-diseased aortas (Arko et al, 2005).

The primary goal of EVAR is aneurysm exclusion and depressurisation. However continued pressurisation secondary to endoleaks or endotension can be associated with late aneurysm rupture with a reported incidence of one per cent (Cho et al, 2004). Diagnosis of rupture after EVAR can be problematic. Female gender and adverse anatomy with short wide and angulated infra-renal necks may be predisposing factors (Brewster et al, 2006). The mortality for late rupture is variable and reported between $43-83 \%$.

As discussed above, aorto-duodenal fistula (ADF) is an abnormal communication between the aorta and usually the fourth part of the duodenum which constitutes a rare but life-threatening complication of aneurysm repair. Until recently, they were primarily associated with open 
AAA repair occurring at a rate $2 \%$ (Bertges et al, 2003). It is believed that local infection leads to intestinal necrosis and subsequent fistula formation. Endotension may also be a contributory factor. Treatment of ADF is graft removal, revascularisation and intestinal repair.

\section{Evidence for type of aneurysm repair: In a nutshell}

\subsection{Open versus laparoscopic AAA repair}

Reviews of published large series of open AAA repair demonstrate consistent short-term (30-day) outcomes: death, 2-5\%; myocardial infarction, 2-8\%; renal failure, 2-5\%; pneumonia, $5 \%$; bleeding, 2-4\%; leg ischaemia 1-4\%; colon ischaemia, 1-2\%; and length of stay 5 to 10 days (Lerderle et al, 2000, Johnston et al, 1998, Huber et al, 2007, Richardson et al, 1991). The short term morbidity and mortality are offset by a low rate of adverse long-term (10 or more years) outcome that include anastomotic aneurysm, 4-10\%; graft infection $1-2 \%$ and thrombosis, 3\% (Biancari et al, 2002; Hallet et al, 1997; Schermehorn et al, 2008). These figures have been used as the benchmark against which the newer, minimal invasive repairs have been judged.

The follow-up results of laparoscopic AAA repair seem to indicate a better post-operative course when compared with standard open repair. Retrospective comparisons with open surgically treated cases are unreliable because the groups are not matched or randomized and are thus subject to the influence of uncontrolled variables. The advantages of the laparoscopic approach over the open surgical approach are likely to be real. Indeed total laparoscopic aortic surgery based on data from the reported laparoscopic AAA repair literature reports better outcomes in terms of post-operative stay when compared to handassisted laparoscopic surgery and open repair (Coggia et al, 2004). However with the advent of EVAR and the pace of technological development the randomized prospective trials required to assess laparoscopic and open AAA repair have not been performed. Laparoscopic AAA repair has thus largely become marginalised because of the wide adoption of EVAR.

\subsection{Open versus EVAR repair}

In modern aortic surgery the question has centred largely on the potential benefits of EVAR in comparison to open repair. Retrospective studies based on large administrative databases comparing open repair with EVAR document impressive superiority of EVAR in early patient outcomes (Schermehorn et al, 2008; Lee et al, 2004; Hua et al, 2005). This advantage of EVAR is all the more impressive when one considers that the EVAR was in general performed upon older and sicker patients. These results have been confirmed in the randomised trials, EVAR-1 and the Dutch Randomized Endovascular Aneurysm Management (DREAM) (Greenhalgh et al, 2004; Prissen et al, 2004). Additionally, two randomized European trials comparing EVAR to open surgery and one randomized trial comparing EVAR to no intervention were published in 2005 (Blankensteijn et al, 2005; EVAR Trial 1, 2005; EVAR Trial 2, 2005). The DREAM trial, randomised 351 patients with asymptomatic AAAs $>5 \mathrm{~cm}$ in diameter with suitable stent graft anatomy to open surgery or EVAR. This study suggested a 30-day benefit in mortality favouring EVAR (Prissen et al, 2004). The trend toward an early mortality advantage was lost, however, 12 months into the 2-year study follow-up (Blankensteijn et al, 2005).

The second trial, from the United Kingdom, EVAR 1, was similar to DREAM in comparing EVAR to open surgery in patients with suitable stent graft anatomy and aneurysm size $\geq 5.5$ 
cm (EVAR Trial 1, 2005). This study randomized 1082 patients. EVAR 1 more clearly demonstrated an early peri-operative mortality benefit for EVAR (Greenhalgh et al, 2004). Blood product use and length of hospital stay also favoured EVAR. In contrast, the primary end point of all-cause mortality did not show a lasting benefit for EVAR at the 4-year study conclusion, although aneurysm-related death was decreased (EVAR Trial 1, 2005). Complication rates and re-intervention rates were much higher for stent graft repair than for open repair. EVAR trial 2 (EVAR Trial 2, 2005) randomized 338 patients $>60$ years of age with aneurysms $\geq 5.5 \mathrm{~cm}$ who were deemed unfit for open surgical repair to EVAR or no intervention (EVAR Trial 2, 2005). Between the two arms of the study, 142 patients died during follow-up, which correlated to a $64 \%$ overall mortality by Kaplan-Meier estimates at 4 years. This study was complicated by long delays in EVAR after randomization and a $27 \%$ patient crossover rate from the no intervention group. In the final analysis, no benefit to EVAR over medical management was detected in either overall mortality or aneurysmrelated mortality for patients unfit for open surgery.

Ongoing in the United States is the Open Versus Endovascular Repair (OVER) trial, a 9-year study that began in 2002 comparing endovascular aneurysm repair with standard open surgery using a multi-centre randomized trial through the Department of Veteran Affairs Cooperative Study Group (Lederle et al, 2006). In comparison with EVAR, open AAA repair has a highly significant 2- to 3-fold increase in mortality, a 1.5- to 2-fold increase in major morbidity, a 12-fold increase in blood transfusion requirement and a 2-fold increase in length of stay and discharge to a long-term care facility.

In conclusion, although early outcome data provided a compelling case for EVAR the outlook became clouded when long term outcomes were considered. This finding is even more pertinent when it is considered that both EVAR 1 and DREAM showed that EVAR was associated with a 4-fold increase in long-term (2-4 years) complications and a 3-fold increase in the need for re-intervention (Greenhalgh et al, 2005; Blankensteijn et al, 2005). Quality of life is heavily in favour of EVAR especially in the weeks and months immediately following the procedure. However after 6 months and longer quality of life is documented to be better in patients with open repair (Greenhalgh et al, 2005; Prissen et al, 2004a; Prissen et al, 2004b). This is likely related to the greater need for radiological surveillance with EVAR. However although earlier studies suggested that EVAR was not cost-effective (Jonk et al, 2007; Prissen et al, 2007) more recent data from the National Institute for Clinical Excellence (NICE) in the United Kingdom suggests EVAR is cost effective (Hay et al, 2009). In addition, the long-term outcomes of EVAR are not fully understood. Indeed a 7- to 8-fold increase in aneurysm-related death after 5 years of follow-up has been observed in goodrisk patients treated with EVAR in comparison with open repair (Eliason et al, 2009).

\subsection{EVAR for small aneurysms}

Whereas randomized clinical trials have focused on establishing the proper use of EVAR for larger aneurysms, its application for the treatment of small aneurysms is still an area of controversy. Early open aneurysm repair for aneurysms $<5.5 \mathrm{~cm}$ in diameter does not confer a long-term survival advantage (Lederle et al, 2002; UK small aneurysm trial, 2002). However, retrospective analysis of the large EUROSTAR database revealed that EVAR for aneurysms with diameters between $4.0 \mathrm{~cm}$ and $5.4 \mathrm{~cm}$ had lower incidence of type I endoleak and improved cumulative freedom from aneurysm-related death relative to two comparison groups with aneurysm diameters of 5.5 to $6.4 \mathrm{~cm}$ and $\geq 6.5 \mathrm{~cm}$ (Peppelenbosch et al, 2004). Level 1 evidence is lacking at this time, but the Positive Impact of EndoVascular 
Options for Treating Aneurysms EarLy (PIVOTAL) and Comparison of Surveillance versus Aortic Endografting for Small Aneurysm Repair (CAESAR) trials were initiated in an attempt to provide such evidence (Cao et al, 2005). Both are device specific, randomize patients with smaller aneurysms to EVAR or surveillance, and use an FDA-approved Medtronic device or the Cook Zenith device, respectively. Until the results of these trials are published, the optimal management of small aneurysms remains ambiguous and a patientspecific approach that takes into account aneurysm morphology, biology, and patient comorbidities should be used.

\subsection{Open versus TEVAR for TAA}

TEVAR benefit to risk ratio is even greater than that encountered with EVAR although TEVAR is more expensive than EVAR. In comparison to open surgery it is associated with significant reduction in blood transfusion requirements, major complications, ITU and hospital length of stay (Murphy et al, 2009). However the total hospital costs are 2-fold higher and the cost margin minus $34 \%$ in comparison with plus $6.2 \%$ for open repair (Ramagnoli et al, 2009). The extra costs for TEVAR were usually a result of the use of multiple devices to treat extensive aneurysms. Clearly, in elderly patients and in those at high risk for open repair, TEVAR is an excellent surgical option for repair. With continuing evaluation of endovascular techniques, comparisons with open repair will be made. Recently, the results from the combined experience of EUROSTAR and the United Kingdom Thoracic Endograft registries have been published (Leurs et al, 2004). From this report, overall 30 -day mortality was $5.4 \%$ for elective cases, and paraplegia was $4 \%$ after aneurysm stenting; 1-year follow-up was obtained for $45 \%$ of patients of the entire cohort with an $80 \%$ survival for aneurysmal disease. Others have reported similar early results (Mitchell et al, 1999; Greenberg et al, 2000; White et al, 2004; Najibi et al, 2002, Hansen et al, 2004; Lambrechts et al, 2003). It remains striking that even with no aortic occlusion during endovascular stenting, neurologic deficit was still significant, ranging as high as $12 \%$ (with stroke as high as $7 \%$ ). The overall long-term survival was $79 \%, 76 \%, 64 \%$, and $35 \%$ at $1,2,5$, and 10 years, respectively after open TAA repair (Svensson et al, 1993). In addition, freedom from reoperation for distal aortic related condition was $96 \%$ at 13 years. Early (1 to 2 years) survival with endovascular stenting has been reported from $73 \%$ to $81 \%$ with freedom from reintervention at $54 \%$ at almost 4 years (Mitchell et al, 1999). This report confirms that open repair for descending thoracic aortic repair remains durable for the long term and does not require multiple reinterventions. Two clinical trials have compared TEVAR with open surgery. The first published in 2002 compared 19 patients with 10 historical controls. The mean length of ITU stay and hospital stay were better in the TEVAR group. This study however was not randomised and follow up was limited (Najibi et al, 2002). The second (non-randomized) study also reported that 30 day mortality was better in the TEVAR group with fewer complications (Bavaria et al, 2007). However the two year survival was similar in both groups. A recent Cochrane review concluded that although such evidence may suggest that endovascular repair can be appropriate in selected patients, high quality studies are needed to produce generalisable conclusions (Abraha et al, 2009).

\section{The future of aortic aneurysm repair}

Aortic surgery has evolved at an exponential rate in the last five decades. The future lies in how we further develop these technologies to improve patient outcome. With the advent of 
screening programmes it is likely in the immediate future that the need for surgery will increase. How to apply these technologies for maximal patient benefit will be the future challenge to the vascular surgeon. In the next decade we can expect continuing improvements in endovascular device design to include the treatment of supra-renal and thoraco-abdominal aneurysms. The role of open repair is likely to diminish raising questions on whether centralization of complex open aortic surgery will be required.. Surgeons will need to have efficient follow-up protocols and evaluate the new stent-grafts in order to continue the advance of aortic aneurysm surgery.

\section{References}

Abraha, I,; Romagnoli, C, Montedori, A, Cirocchi, R (2009) Thoracic stent graft versus surgery for thoracic aneurysm. Cochrane Database Systematic Review, Vol 21, No. 1, pp. CD006796

Antoniou, GA.; Koutsias, S, Antoniou, SA, Georgiakakis, A, Lazarides, MK, Giannoukas, AD (2009) Outcome after endovascular stent graft repair of aortoenteric fistula: A systematic review. Journal of Vascular Surgery, Vol 49, pp. 782-789

Arko, FR,; Heikkinen M, Lee, ES, Bass, A, Alsac, JM, Zairns, CK (2005) Illiac fixation length and resistance to in-vivo stent-graft displacement. Journal of Vascular Surgery, Vol 41, No. 4, pp. 664-671

Bavaria, JE,; Appoo, JJ, Makaroun, MS, Verter, J, Yu, ZF, Mitchell, RS (2007) Endovascular stent grafting versus open surgical repair of descending thoracic aortic aneurysms in low-risk patients: a multicenter comparative trial. Thoracic and Cardiovascular Surgery, Vol 133, No 2, 369-377

Bahnson, HT (1953) Definitive treatment of saccular aneurysms of the aorta with excision of sac and aortic suture. Surgery, Gynecology \& Obstetrics, Vol 96, No 4, pp. 383-402

Barratt, J;; Parajasingam, R, Sayers, RD, Feehally, J (2000) Outcome of acute renal failure following surgical repair of ruptured abdominal aortic aneurysms. European Journal of Vascular and Endovascular Surgery, Vol 20, No. 2, pp. 163-168

Becquemin, JP,; Kelley, L, Zubilewicz T (2004) Outcomes of secondary interventions after aortic aneurysm endovascular repair. Journal of Vascular Surgery, Vol 39, No. 2, pp.298-305

Bertges, DJ,; Villella, ER, Makaroun, MS (2003) Aortoenteric fistula due to endoleak coil embolization after endovascular AAA repair. Journal of Endovascular Therapy, Vol. 10, No. 1, pp. 130-135

Biancari, F,; Ylonen, K, Anttila, V, Juvonen, J, Romsi, P, Satta, J, Juvonen, T (2002) Durability of open repair of infrarenal abdominal aortic aneurysm: a 15-year follow-up study. Journal of Vascular Surgery, Vol 35, No. 1, pp. 87-93

Blankensteijn, JD,; de Jong, SE, Prinssen, M, van der Ham, AC, Buth J, van Sterkenburg, SM, Verhagen, HJ, Buskens, E, Grobbee, DE (2005) Dutch Randomized Endovascular Aneurysm Management (DREAM) Trial Group. Two-year outcomes after conventional or endovascular repair of abdominal aortic aneurysms. New England Journal of Medicine, Vol 352, No. 23, pp. 2398-2405.

Brewster, DC (2002) Do current results of endovascular abdominal aortic aneurysm repair justify more widespread use? Surgery, Vol 131, No. 4, pp. 363-367 
Brewster, DC,; Cronenwett, JL, Hallet Jr, JW, Johnston, KW, Krupski, WC, Matsumura, JS (2003) Guidelines for the treatment of abdominal aortic aneurysms. Report of a subcommittee of the Joint Council of the American Association for Vascular Surgery and Society for Vascular Surgery. Journal of Vascular Surgery, Vol 37, No. 5, pp. 1106-1117

Brewster, DC,; Jones, JE, Chung, TK, Lamuraglia, GM, Kwolek, CJ, Watkins, MT, Hodgman, TM, Cambria, RP (2006) Long-term outcomes after endovascular abdominal aortic aneurysm repair: the first decade. Annals of Surgery, Vol 244, No. 3, pp. 426-438

Cao P, CAESAR Trial Collaborators. Comparison of surveillance vs Aortic Endografting for Small Aneurysm Repair (CAESAR) trial: study design and progress. European Journal of Vascular and Endovascular Surgery, Vol 30, No. 3, pp. 245-251.

Castronuovo, JJ,; James, KV, Resnikoff, M, McLean, ER, Edoga, JK (2000) Laparoscopicassisted abdominal aortic aneuysmectomy. Journal of Vascular Surgery, Vol 32, No. 2, pp. 224-233

Cerveira, JJ,; Halpern, VJ , Faust, G, Cohen, JR (1999) Minimal incision abdominal aortic aneurysm repair . Journal of Vascular Surgery, Vol 30, No. 6, pp. 977-979

Chaikof, EL,; Blankensteijn, JD, Harris, PL, White, GH, Zarins, CK, Bernhard, VM, Matsumura, JS, May, J, Veith, FJ, Fillinger, MF, Rutherford, RB, Kent, KC (2002) Ad Hoc Committee for Standardized Reporting Practices in Vascular Surgery of The Society for Vascular Surgery/American Association for Vascular Surgery. Reporting standards for endovascular aortic aneurysm repair. Journal of Vascular Surgery. Vol 35, pp. 1048-1060

Chiu, KM,; Lin, TY, Chu, SH, Chen JR (2008) Total laparoscopic repair for abdominal aortic aneurysm. J Formos Med Assoc, Vol 107, No. 8, pp. 667-672

Cho, JS,; Dillavou, ED, Rhee, RY, Makaroun, MS (2004) Late abdominal aneurysm enlargement after endovascular repair with the Excluder device. Journal of Vascular Surgery, Vol 39, No. 6, pp. 1236-1242

Clagett GP, (2008) EVAR, TEVAR, FEVAR, too far? Perspectives in Vascular and Endovascular Therapy, Vol 20, No. 2, pp 115-119

Coggia, M, Javerliat, I, Di Centa, I, Colacchi, G, Cerceau, P, Kitzis, M, Goeau-Brissonniere, OA (2004) Total laparoscopic infrarenal aortic aneurysm repair: preliminary results Journal of Vascular Surgery, Vol 40, No. 3, pp. 448-454

Coggia, M,; Cerceau, P, Di Centa, I, Javerliat, I, Colacchio, G, Goeau-Brissonniere, OA (2008) Total laparoscopic juxtarenal abdominal aortic aneurysm repair. Journal of Vascular Surgery, Vol 48, No. 1, pp. 37-42

Cooley, DA \& De Bakey, ME (1956) Resection of entire ascending aorta in fusiform aneurysm using cardiac bypass. Journal of American Medical Association, Vol 162, No.12, pp. 1158-1159

Corbett; TJ,; Callanan, A, Morris, LG, Doyle, BJ, Grace, PA, Kavanagh, EG, McGloughlin, TM (2008) A review of the in vivo and in vitro biomechanical behaviour and performace of post-operative abdominal aortic aneurysm and implanted stentgrafts. Journal of Endovascular Therapy, Vol 15, No. 4, pp. 468-484 
Coselli, JS.; LeMaire, SA, Conklin, LD, Adams, GJ (2004) Left heart bypass during descending thoracic aortic aneurysm repair does not reduce the incidence of paraplegia. Annals of Thoracic Surgery, Vol 77, pp. 1298-1303

Cowan Jr, JA,; Dimick, JB, Henke, PK, Rectenwald, J, Stanley, JC, Upchurch Jr, GR (2006) Epidemiology of aortic aneurysm repair in the United States from 1993 to 2003. Annals of New York Academy of Science, Vol 1085: 1-10

Crawford, ES,; Crawford, JL, Safi, HJ, Coselli, JS, Hess, KR, Brooks, B, Norton, HJ, Glaeser, DH (1986) Thoracoabdominal aortic aneurysms: preoperative and intraopertaive factors determining immediate and long-term results of operations in 605 patients. Journal of Vascular Surgery, Vol 3, No. 3, pp. 389-404

Creech, O (1966) Endoaneurysmorrhaphy and treatment of aortic aneurysm. Annals of Surgery, Vol 164, pp. 935-946

Dajczman, E,; Gordon, A, Kreisman, H, Wolkove, N (1991) Long-term postthoracotomy pain. Chest, Vol 99, No. 2, pp.270-274

Dake, MD,; Miller, DC, Semba, CP, Mitchell, RS, Walker, PJ, Liddell, RP (1994) Transluminal placement of endovascular stent-grafts for the treatment of descending thoracic aortic aneurysms. New England Journal of Medicine, Vol 331, No. 26, pp. 1729-34

De Bakey, ME.; Crawford, ES, Cooley, DA, Morris Jr, GC (1957). Successful resection of fusiform aneurysm of aortic arch with replacement by homograft. Surgery, Gynecology \& Obstetrics, Vol 105, No.6, pp. 657-664

Deterling, RA \& Bhonslay, SB (1955) An evaluation of synthetic materials and fabrics suitable for blood vessel replacement. Surgery, Vol 38, No.1, pp. 71-91

Dion, YM,; Katkhouda, N, Roleau, C, Aucoin, A (1993) Laparoscopic-assisted aortobifemoral bypass . Surgical Laparoscopy Endoscopy, Vol 3, No. 5, pp. 425-429

Dorros, G \& Cohn, JM (1996) Adenosine-induced transient cardiac asystole enhances precise deployment of stent-grafts in the thoracic or abdominal aorta. Journal of Endovascular Surgery, Vol 3, No. 3, pp. 270-272

Dubost, C,; Allary, M, Oeconomos, N (1951) Aneurysm of the abdominal aorta treated by resection and graft. Sem Hop, Vol 27, No. 69, pp. 2678-2785

Edoga, JK,; Asgarian; K, Singh; D, James; KV, Romanelli; J, Merchant, S, Romano, D, Joostema, B, Street, J. Laparoscopic surgery for abdominal aortic aneurysm: technical elements of the procedure and a preliminary report of the first 22 patients. Surgical Endoscopy, Vol 12, No. 8, pp. 1064-1072

Engle, J,; Safi, HJ, Miller 3rd, CC, Campbell, MP, Harlin, SA, Letsou, GV, Lloyd MD, Root DB (1999) The impact of diaphragm management on prolonged ventilator support after thoracoabdominal aortic repair. Journal of Vascular Surgery, Vol 29, No. 1, pp. 150156

Eliason, JL, \& Upchurch Jr, GR (2009) Endovascular treatment of aortic aneurysms: state of the art. Current Treatment Options in Cardiovascular Medicine, Vol 11, No. 2, pp. 136145

El-Sabrout, RA., \& Reul, GJ (2001) Suprarenal or supraceliac aortic clamping during repair of infrarenal abdominal aortic aneurysms. Texas Heart Institute Journal, Vol 28, No.4, pp. 254-264 
Estrera, AL.; Miller 3rd, CC, Huynh, TT (2003) Preoperative and operative predictors of delayed neurologic deficit following repair of thoracoabdominal aortic aneurysm. Journal of Thoracic Cardiovascular Surgery, Vol 126, pp.1288-1294

Etz, CD,; Di Luozzo, G, Bello, R, Luehr, M, Khan, MZ, Bodian, CA, Griepp, RB, Plestis, KA (2007) Pulmonary complications after descending thoracic and thoracoabdominal aortic aneurysm repair: predictors, prevention and treatment. Annals of Thoracic Surgery, Vol 83, No. 2, pp. S870-S876

EVAR Trial Participants (2005) Endovascular aneurysm repair versus open repair in patients with abdominal aortic aneurysm (EVAR trial 1): randomised controlled trial. Lancet, Vol 365, pp. 2179-2186

EVAR Trial Participants (2005) Endovascular aneurysm repair and outcome in patients unfit for open repair of abdominal aortic aneurysm (EVAR trial 2): randomised controlled trial. Lancet, Vol 365, pp. 2187-2192.

Fairman, RM,; Nolte, L, Snyder, SA, Chuter, TA, Greenberg, RK, Zenith Investigators (2006) Factors predictive of early or late aneurysm sac size change following endovascular repair. Journal of Vascular Surgery, Vol 43, No. 4, pp. 649-656

Fuchs, RJ,; Lee, WA, Seubert, CN, Gelman, S (2003) Transient paraplegia after grafting of a descending thoracic aortic aneurysm treated with cerebrospinal fluid drainage. Journal of Clinical Anesthesiology, Vol 15, No. 1, pp. 59-63

Fukada, J,; Morishita, K, Kawaharada, N, Yamada, A, Harada, N, Abe, T (2002) Lessinvasive thoracic aneurysm repair. Annals Thoracic Surgery, Vol 74, No. 4, pp. 12441246

Gonzalez-Fajardo JA, Gutierrez V, San Roman, JA, Serrador, A, Arreba E, Del Rio, L, Martin, M, Carrera, S, Vaquero, C (2002) Utility of intraopertaive transesophgeal echocardiography during endovascular stent-graft repair of acute thoracic aoric dissection. Annals of Vascular Surgery, Vol 16, No. 3, pp. 297-303

Green, RM.; Ricotta, JJ, Ouriel, K, DeWeese, JA (1989) Results of supraceliac aortic clamping in the difficult elective resection of infrarenal abdominal aortic aneurysm. Journal of Vascular Surgery, Vol 9, pp. 124-134

Greenberg, R,; Resch, T, Nyman, U, Lindh, M, Brunkwall, J, Brunkwall P, Malina, M, Koul, B, Lindblad, B, Ivancev K (2000). Endovascular repair of descending thoracic aortic aneurysmsal early experience with intermediate-term follow-up. Journal of Vascular Surgery, Vol 31, pp. 147-156

Greenhalgh RM, Brown LC, Kwong GP, Powell JT, Thompson SG, EVAR Trial Participants (2004) Comparison of endovascular aneurysm repair with open repair in patients with abdominal aortic aneurysm (EVAR trial 1), 30-day operative mortality results: randomised controlled trial. Lancet, Vol 364, No. 9437, pp. 843-848

Gross, RE.; Hurwitt, ES. \& Bill, AH Jr (1948) Preliminary observations on the use of human arterial grafts in the treatment of certain cardiovascular defects. New England Journal of Medicine, Vol 239, No.16, pp. 578

Hallett Jr, JW,; Marshall, DM, Petterson, TM, Gary, DT, Bower, TC, Cherry Jr, KJ, Gloviczki, P, Pairolero, PC (1997) Graft-related complications after abdominal aortic aneurysm repair: reassurance from a 36-year population-based experience. Journal of Vascular Surgery, Vol 25, No. 2, pp. 277-284 
Hansen, CJ,; Bui, H, Donayre, CE, Aziz, I, Kim, B, Kopchok, G, Walot, I, Lee, J, Lippmann, M, White, RA (2004). Complications of endovascular repair of high-risk and emergent descending thoracic aortic aneurysms and dissections Journal of Vascular Surgery, Vol 40, No. 2, pp. 228-234

Haulon, S \& O'Brien N (2011) Advances in endovascular repair for complex aneurysms. British Journal of Surgery, Vol 98, No.2, pp 163-165

Hay, N,; McCraken, F, Richardson, J, Barnett, D (2009) Endovascular stent-grafts for the treatment of abdominal aortic aneurysms: NICE technology appraisal guidance. Heart, Vol 95, pp. 1798-1800

Hobo, R, \& Buth J (2006) Secondary interventions following endovascular abdominal aortic aneurysm repair using current endografts: a EUROSTAR report. Journal of Vascular Surgery, Vol 43, No. 5, pp. 896-902.

Hua, HT,; Cambria, RP, Chuang, SK, Stoner, MC, Kwolek, CJ, Rowell, KS, Khuri, SF, Henderson, WG, Brewster, DC, Abbott, WM (2005) Early outcomes of endovascular versus open abdominal aortic aneurysm repair in the National Surgical Quality Improvement Program-Private Sector (NSQIP-PS). Journal of Vascular Surgery, Vol 41, No. 3, pp. 382-389

Huber, TS,; Wang, JG, Derrow, AE, Dame, DA, Ozaki, CK, Zelenock, GB, Flynn, TC, Seeger, JM (2001) Experience in the United States with intact abdominal aortic aneurysm repair. Journal of Vascular Surgery, Vol 33, No. 2, pp. 304-310

Iezzi, R \& Cotroneo AR (2001) Endovascular repair of abdominal aneurysms: CTA evaluation of contraindications. Abdominal Imaging, Vol 31, No. 6, pp. 722-731

Ishimaru, S (2004) Endografting of the aortic arch. Journal of Endovascular Therapy, Vol 11: pp. I162-I171

Iyer, VS,; Mackenzie, KS, Corriveau, MM, Steinmetz, OK (2007) Reversible endotension associated with excessive warfarin anticoagulation. Journal of Vascular Surgery, Vol 45, No. 3, pp. 600-602

Jackson, BM,; Carpenter JP, Fairman, RM, Moser, GW, Pochettino, A, Woo EY, Bavaria, JE (2007) Anatomic exclusion from endovascular repair of thoracic aortic aneurysm. Journal of Vascular Surgery, Vol 45, No. 4, pp. 662-666

Jacobs, TS,; Won, J, Gravereaux, EC, Faries, PL, Morrissey, N, Teodorescu, VJ, Hollier, LH, Marin, ML (2003) Mechincal failure of prosthetic human implants: a 10-year experience with aortic stent graft devices. Journal of Vascular Surgery, Vol 37, No. 1, pp. 16-26

Jimenez, JC,; Smith, MM, Wilson, SE (2004) Sexual dysfunction in men after open or endovascular repair of abdominal aortic aneurysms. Vascular, Vol 12, No. 3, pp. 186-191

Johnston, KW \& Scobie TK (1988) Multicenter prospective study of non-ruptured abdominal aortic aneurysms. Population and operative management. Journal of Vascular Surgery, Vol 7, No. 1, pp. 69-81

Jones, JE,; Atkins; MD, Brewster; DC, Chung; TK, Kwolek; CJ, LaMuraglia; GM, Hodgman; TM, Cambria, RP (2007) Persistent type 2 endoleak after endovascular repair of abdominal aortic aneurysm is associated with adverse late outcomes. Journal of Vascular Surgery, Vol 46, No. 1, pp. 1-8 
Jonker, FH,; Trimarchi, S, Verhagen, HJ, Moll, FL, Sumpio, BE, Muhs, BE (2010) Metaanalysis of open versus endovascular repair for ruptured descending thoracic aortic aneurysm. Journal of Vascular Surgery, Vol 51, No. 4, pp. 1032.e1-1032.e2.

Kahn ,RA,; Marin, ML, Hollier, L, Parsons, R, Griepp, R (1998) Induction of ventricular fibrillation to facilitate endovascular stent grat repair of thoracic aortic aneurysm. Anesthesiology, Vol 88, No. 2, pp. 534-536

Kamineni, R \& Heuser, RR (2004) Abdominal aortic aneurysm: a review of endoluminal treatment. Journal of Interventional Cardiology, Vol 17, No. 6, pp. 437-445

Kim, GS,; Ahn, HJ, Kim, WH, Kim, MJ, Lee, SH (2011) Risk factors for post-operative complications after open infrarenal abdominal aortic aneurysm repair in Koreans. Yonsei Medical Journal, Vol 52, No. 2, pp. 339-346

Kirby, TJ \& Rice, TW (1993) Thorascopic lobectomy. Annals of Thoracic Surgery, Vol 56, No. 3, pp. 784-786

Kline, RG,; D'Angelo, AJ, Chen, MHM, Halpern, VJ, Cohen, JR. Laparoscopically assisted abdominal aortic aneurysm repair: first 20 cases . Journal of Vascular Surgery, Vol 27, No. 1, pp. 81-87

Kolvenbach, R,; Schwierz, E, Wasilljew, S, Miloud, A, Peurschel, A, Pinter, L. Total laparoscopically and robotically assisted aneurysm surgery: a critical evaluation . Journal of Vascular Surgery, Vol 39, No. 4, pp. 771-776

Kuhan, G \& Raptis, S (1997) 'Trash foot' following operations involving the abdominal aorta. Australian and New Zealand Journal of Surgery, Vol 67, No. 1, pp. 21-24

Kurosawa, K,; Ohta, H, Sumi, M, Ohki, T (2007) Physiologic monitoring data: will it change our follow-up paradigms? Seminars in Vascular Surgery, Vol 20, No. 2, pp. 115-120

Lam, CR, \& Aram, HH (1951) Resection of the descending thoracic aorta for aneurysm: a report of the use of a homograft in a case and experimental study. Annals of Surgery, Vol 134, No. 4, pp. 743-752

Lambrechts, D,; Casselman, F, Schroeyers, P, De Geest, R, D'Haenens, P, Degrieck, I (2003) Endovascular treatment of the descending thoracic aorta. European Journal of Vascular and Endovascular Surgery, Vol 26, No. 4, pp. 437-444

Lazarus, HM (1988) Intraluminal graft device, system and method. US patent number $4,787,899$

Lee, WA,; Carter, JW, Upchurch, G, Seeger, JM, Huber TS (2004) Perioperative outcomes after open and endovascular repair of intact abdominal aortic aneurysms in the United States during 2001. Journal of Vascular Surgery, Vol 39, No. 3, pp. 491-496

Lee, WA,; Brown, MP, Nelson, PR, Huber, TS. Total percutaneous access for endovascular aortic aneurysm repair ("Preclose" technique). Journal of Vascular Surgery, Vol 45, No. 6, pp. 1095-1101.

Lederle, FA,; Johnson, GR, Wilson, SE, Cute, EP, Hye, RJ, Makaroun, MS, Barone, GW, Bandyk, D, Moneta, GL, Makhoul, RG (2000) The aneurysm detection and management study screening program: validation cohort and final results. Aneurysm Detection and Management Veterans Affairs Cooperative Study Investigators. Archives of Internal Medicine, Vol 160, No. 19, pp 1425-1430

Lederle, FA,; Wilson, SE, Johnson, GR, Reinke, DB, Littooy, FN, Acher, CW, Ballard, DJ, Messina, LM, Gordon, IL, Chute, EP, Krupski, WC, Busuttil, SJ, Barone, GW, 
Sparks, S, Graham, LM, Rapp, JH, Makaroun, MS, Moneta, GL, Cambria, RA, Makhoul, RG, Eton, D, Ansel, HJ, Freischlag, JA, Bandyk, D (2002) Aneurysm Detection and Management Veterans Affairs Cooperative Study Group. Immediate repair compared with surveillance of small abdominal aortic aneurysms. New England Journal of Medicine, Vol 346, No 19, pp. 1437-1444.

Lederle, FA (2006) A summary of the contributions of the VA cooperative studies on abdominal aortic aneurysms. Annals of New York Academy of Sciences, Vol 1085, pp. 29-38

Leurs, L,; Bell, R, Degrieck, Y, Thomas, S, Hobo, R, Lundbom, J; EUROSTAR; UK Thoracic Endograft Registry (2004) Endovascular treatment of thoracic aortic diseasescombined experience from the EUROSTAR and United Kingdom Thoracic Endograft registries. Journal of Vascular Surgery, Vol 40, No. 4, pp.670-679

Lin, P,; Bush, RL, Katzman, JB, Zemel, G, Puente, OA, Katzen, BT, Lumsden, AB (2003) Delayed aortic aneurysm enlargement due to endothension after endovascular abdominal aortic aneurysm repair. Journal of Vascular Surgery, Vol 38, No. 4, pp. 840-842

Major, RH (1954) A History of Medicine, Illinois, Charles C. Thomas, Chapter I, pp. 51-204

McPhee, JT,; Hill,JS, Eslami, MH (2007) The impact of gender on presentation, therapy, and mortality of abdominal aortic aneurysm in the United States, 2001-2004. Journal of Vascular Surgery, Vol 45, No. 5, pp. 891-899

McPhee, JT; Robinson 3rd, WP, Eslami, MH, Arous EJ, Messina, LM, Schanzer, A (2011) Surgeon case volume, not institution case volume, is the primary determinant of inhospital mortality after elective open abdominal aortic aneurysm repair. Journal of Vascular Surgery, Vol 53, No. 3, pp. 591-599

Merten, GJ,; Burgess, WP, Gray, LV, Holleman, JH, Roush, TS, Kowalchuk, GJ, Bersin, RM, Van Moore, A, Simonton 3rd, CA, Rittase, RA, Norton, HJ, Kennedy, TP (2004) Prevention of contrast-induced nephropathy with sodium bicarbonate: a randomised controlled trial. Journal of American Medical Association, Vol 291, No. 19, pp. 2328-2334

Mitchell, RS,; Miller, DC, Dake, MD, Semba, CP, Moore, KA, Sakai, T (1999) Thoracic aortic aneurysm repair with an endovascular stent graft the "first generation.". Annals of Thoracic Surgery, Vol 67, No. 6, 1971-1974

Moon, MC,; Morales, JP, Greenberg, RK (2007) The aortic arch and ascending aorta: are they within the endovascular realm? Seminars in Vascular Surgery, Vol 20, No. 2, pp. 97107

Murphy, EH,; Beck, AW, Clagett, GP, DiMaio, JM, Jessen, ME, Arko, FR (2009) Combined aortic debranching and thoracic endovascular aneurysm repair (TEVAR) effective but at a cost. Annals of Surgery, Vol 144, No. 3, pp. 222-227

Najibi, S,; Terramani, TT, Weiss, VJ, MacDonald, MJ, Lin, PH, Redd, DC, Martin, LG, Chaikof, EL, Lumsden, AB (2002) Endoluminal versus open treatment of descending thoracic aortic aneurysms. Journal of Vascular Surgery, Vol 36, No. 4, pp. 732-737

Parodi, JC,; Palmaz, JC, Barone, HD (1991) Transfemoral intraluminal graft implantation for abdominal aortic aneurysms. Annals of Vascular Surgery, Vol 5, No. 6, pp. 491-499 
Peppelenbosch, N,; Buth, J, Harris, PL, van Marrewijk, C, Fransen, G, EUROSTAR Collaborators (2004) Diameter of abdominal aortic aneurysm and outcome of endovascular aneurysm repair: does size matter? A report from EUROSTAR. Journal of Vascular Surgery, Vol 39, No. 2, pp. 288-297.

Prinssen, M,; Verhoeven, EL, Buth, J, Cuypers, PW, van Sambeek, MR, Balm, R, Buskens, E, Grobbee, DE, Blankensteijn, JD (2004) Dutch Randomized Endovascular Aneurysm Management (DREAM) Trial Group. A randomized trial comparing conventional and endovascular repair of abdominal aortic aneurysms. New England Journal of Medicine, Vol 351, No. 16, pp. 1607-1618

Prissen, M,; Buskens, E, Nolthenius, RP, van Sterkenburg, SM, Teijink, JA, Blankensteijn, JD (2004) Sexual dysfunction after conventional and endovascular AAA repair: results of the DREAM Trial. Journal of Endovascular Therapy, Vol 11, No. 6, pp. 613-620

Prissen, M,; Buskens, E, de Jond, SE, Buth, J, Mackaay, AJ, van Sambeek, MR, Blankensteijn, JD, DREAM Trial participants (2007) Cost-effectiveness of conventional and endovascular repair of abdominal aortic aneurysms: results of a randomised trial. Journal of Vascular Surgery, Vol 46, No. 5, pp. 883-890

Richardson, JD \& Main, KA (1991) Repair of abdominal aortic aneurysms. A statewide experience. Archives of Surgery, Vol 126, No. 5, pp. 614-616

Rickenbach, S,; Hassani, O, Thaveau, F, Bensimon, Y, Jacquot, X, Tally, SE, Geny, B, Eisenmann, B, Charpentier, A, Chakfe, N, Kretz, JG (2004) Current outcome of elective open repair for infrarenal abdominal aortic aneurysm. Annals of Vascular Surgery, Vol 18, No. 6, pp. 704-709

Rudnick, M \& Feldman H (2008) Contrast-induced nephropathy: what are the true clinical consequences? Clinics of Journal of American Society of Nephrology, Vol 3, No. 1, pp. 263-272

Saers, SJ \& Scheltinga, MR (2005) Primary aortoenteric fistula. British Journal of Surgery, Vol 92, No. 2, pp. 143-52

Sampram, ESK.; Karafa, MT, Mascha, EJ (2003). Nature, frequency and predictors of secondary procedures after endovascular repair of abdominal aortic aneurysm . Journal of Vascular Surgery. Vol 37, pp. 930-937

Sasaki, T,; Ohsawa, S, Ogawa, M, Mukaida, M, Nakajima, T, Komodo, K, Tachieda, R, Niinuma, H, Kawazoe, K (2000) Postoperative renal function after an abdominal aortic aneurysm repair requiring a suprarenal aortic cross-clamp. Surgery Today, Vol 30, No.1, pp. 33-36

Schermerhorn, ML,; O’Malley, AJ, Jhaveri, A, Cotterill, P, Pomposelli, F, Landon, BE (2008) Endovascular vs. open repair of abdominal aortic aneurysms in the Medicare population. New England Journal of Medicine, Vol 358, No. 5, pp. 464-474

Song ,Y.; Liu, Q, Shen, H, Jia, X, Zhang, H, Qiao, L (2008) Diagnosis and management of primary aortoenteric fistulas-experience learned from eighteen patients. Surgery, Vol 143, pp. 43-50

Svensson, LG,; Crawford, ES, Hess, KR, Coselli, JS, Safi, HJ (1993) Variables predictive of outcome in 832 patients undergoing repairs of the descending thoracic aorta. Chest, Vol 104, No. 4, pp.1248-1253. 
Tanski III W \& Fillinger M (2007) Outcomes of original and low-permeability Gore Excluder endoprosthesis for endovascular abdominal aortic aneurysm repair. Journal of Vascular Surgery, Vol 45, No. 2, pp. 243-249

Thompson JE (1998) History of vascular surgery. Chapter 6 In: Surgery: basic science and clinical evidence, pp. 1299-1312

United Kingdom Small Aneurysm Trial Participants (2002) Long-term outcomes of immediate repair compared with surveillance of small abdominal aortic aneurysms. New England Journal of Medicine, Vol 346, No. 19, pp. 1445-1452.

Wald, R,; Waikar, SS, Liangos, O, Pereira, BJ, Chertow, GM, Jaber, BL (2006) Acute renal failure after endovascular vs open repair of abdominal aortic aneurysm. Journal of Vascular Surgery, Vol 43, No.3, pp. 460-466

White, GH,; Yu, W, May, J (1996) Endoleak-a proposed new terminology to describe incomplete aneurysm exclusion by an endoluminal graft. Journal of Endovascular Surgery, Vol 3, No. 1, pp. 124-125.

White, RA,; Donayre, CE, Walot, I, Lippmann, M, Woody, J, Lee, J, Kim, N, Kopchok, GE, Fogarty, TJ (2001) Endovascular exclusion of descending thoracic aortic aneurysms and chronic dissections initial clinical results with the AneuRx device. Journal of Vascular Surgery, Vol 33, No. 5, pp. 927-934

Willard, JC.; \& Nasbeth, DC (1974) Visceral infarction following aortic surgery. Annals of Surgery, Vol 180, pp. 312-318

Wolf, YG,; Tillich, M, Lee, WA, Rubin, GD, Fogarty, TJ, Zairns, CK (2001) Impact of aortoiliac tortuosity on endovascular repair of abdominal aortic aneurysms: evaluation of 3D computer-based assessment. Journal of Vascular Surgery, Vol 34, No. 4, pp. 594-599

van Bommel, EF,; van der Veer, SJ, Hendriksz, TR, Bleumink, GS (2008) Persistent chronic peri-aortitis ('inflammatory aneurysm') after abdominal aortic aneurysm repair: systematic review of literature. Vascular Medicine, Vol 13, No. 4, pp. 293-303

Velazquez, OC,; Larson, RA, Baum, RA, Carpenter, JP, Golden, MA, Mitchell, ME, Pyeron, A, Barker, CF, Fairman, RM (2001) Gender-related differences in infrarenal aortic aneurysm morphologic features: issues relevant to Ancure and Talent endografts. Journal of Vascular Surgery, Vol 33, pp. S77-S84

Verhoeven, ELG,; Tiellin; JFS, Prins, TR (2004) Frequency and outcome of re-interventions after endovascular repair for abdominal aortic aneurysm: a prospective cohort study. European Journal of Vascular and Endovascular Surgery. Vol 28, No. 4, pp. 357364

Volodos, NL,; Karpovich, IP, Troyan, VI, Kalashnikova, YuV, Chekhanin, VE, Ternyuk, NE, Neoneta, AS, Ustinov, NI, Yakovenko, LF (1991) Clinical experiences of the use of self-fixing synthetic prostheses for remote endoprosthetics of the thoracic and the abdominal aorta and iliac arteries through the femoral artery and as intraoperative endoproshesis for aorta reconstruction. Vasa Suppl, Vol 33, pp. 95-99

Voorhoeve, R.; Moll, FL, de Letter, JA, Bast, TJ, Wester, JP, Slee, PH (1996) Primary aortoenteric fistula: Report of eight new cases and review of the literature. Annals of Vascular Surgery, Vol 10, No. 1, pp. 40-48 
Yamada, N,; Okita, Y, Minatoya, K, Tagusari, O, Ando, M, Takamiya, M, Kitamura, S (2000) Preoperative demonstration of the Adamkiewicz artery by magnetic resonance angiography in patients with descending or thoracoabdominal aortic aneurysms. European Journal of Cardiovascular Surgery, Vol 18, No. 1, pp. 104-11

Jonk, YC,; Kane, RL, Lederle, FA, MacDonald, R, Cutting, AH, Wilt, TJ (2007) Costeffectiveness of abdominal aortic aneurysm repair: a systematic review. International Journal of Technology Assessment in Health Care, Vol 23, No. 2, pp. 205215

Zarins, CK,; Bloch, DA, Crabtree, T, Matsumoto, AH, White, RA, Fogarty, TJ (2003) Stent graft migration after endovascular aneurysm repair: importance of proximal fixation. Journal of Vascular Surgery, Vol 38, No. 6, 1264-1272 


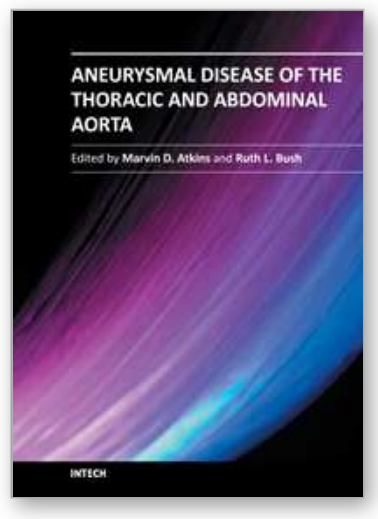

\author{
Aneurysmal Disease of the Thoracic and Abdominal Aorta \\ Edited by Dr. Ruth Bush
}

ISBN 978-953-307-578-5

Hard cover, 226 pages

Publisher InTech

Published online 16, December, 2011

Published in print edition December, 2011

The first successful open surgical repair of an abdominal aortic aneurysm was in 1951 by Dubost and represented a tremendous milestone in the care of this challenging disease. The introduction of endovascular repair in 1991 by Parodi furthered the care of these patients by allowing for lower morbidity and mortality rates and also, enabling surgeons to extend surgical treatment to patients traditionally deemed too high of a surgical risk. This new book on Aortic Disease covers many interesting and vital topics necessary for both the practicing surgeon as well as a student of vascular disease. The book starts with background information on the evolution of aortic management from traditional open surgical repair to modern endovascular therapies. There is also a chapter covering the data supporting current treatment modalities and how these data have supported modern management. Also, the use of endovascular means for care of the challenging situation of ruptured aneurysms is discussed. In addition to management of abdominal aneurysm, there is a chapter on treatment of aneurysms of the ascending aorta. Along with surgical treatment, one must also understand the molecular basis for how blood vessels remodel and thus, the role of cathepsins in aortic disease is elucidated. Lastly, chapters discussing the perioperative management of radiation exposure and ultrasound-guided nerve blocks as well as the need for high-quality postoperative nutrition will lend well to a full understanding of how to management patients from presentation to hospital discharge. We hope you enjoy this book, its variety of topics, and gain a fuller knowledge of Aneurysmal Disease of the Thoracic and Abdominal Aorta.

\title{
How to reference
}

In order to correctly reference this scholarly work, feel free to copy and paste the following:

Ricky Harminder Bhogal and Richard Downing (2011). The Evolution of Aortic Aneurysm Repair: Past Lessons and Future Directions, Aneurysmal Disease of the Thoracic and Abdominal Aorta, Dr. Ruth Bush (Ed.), ISBN: 978-953-307-578-5, InTech, Available from: http://www.intechopen.com/books/aneurysmal-disease-of-thethoracic-and-abdominal-aorta/the-evolution-of-aortic-aneurysm-repair-past-lessons-and-future-directions

\section{INTECH}

open science | open minds

\section{InTech Europe}

University Campus STeP Ri

Slavka Krautzeka 83/A

51000 Rijeka, Croatia

Phone: +385 (51) 770447

\section{InTech China}

Unit 405, Office Block, Hotel Equatorial Shanghai

No.65, Yan An Road (West), Shanghai, 200040, China

中国上海市延安西路65号上海国际贵都大饭店办公楼 405 单元

Phone: +86-21-62489820 
Fax: +385 (51) 686166

Fax: +86-21-62489821

www.intechopen.com 
(C) 2011 The Author(s). Licensee IntechOpen. This is an open access article distributed under the terms of the Creative Commons Attribution 3.0 License, which permits unrestricted use, distribution, and reproduction in any medium, provided the original work is properly cited. 